NBSIR 81-2286

\title{
The Characterization of Auto Headlight Glass by Refractive Index and Density
}

Prepared by the Law Enforcement Standards Laboratory National Engineering Laboratory

Washington, DC 20234

October 1981

Prepared for the

Vational Institute of Justice QC I.S. Department of Justice 100 Vashington, DC 20531

.456

$81-2286$

1981

C. 2 


\section{ABOUT THE TECHNOLOGY ASSESSMENT PROGRAM}

The Technology Assessment Program is sponsored by the Office of Development, Testing, and Dissemination of the National Institute of Justice (NIJ), U.S. Department of Justice. The program responds to the mandate of the Justice System Improvement Act of 1979, which created NIJ and directed it to encourage research and development to improve the criminal justice system and to disseminate the results to Federal, state, and local agencies.

The Technology Assessment Program is an applied research effort that determines the technological needs of justice system agencies, sets minimum performance standards for specific devices, tests commercially available equipment against those standards, and disseminates the standards and the test results to criminal justice agencies nationwide and internationally.

The program operates through:

The Technology Assessment Program Advisory Council (TAPAC) consisting of nationally recognized criminal justice practitioners from Federal, state, and local agencies, which assesses technological needs and sets priorities for research programs and items to be evaluated and tested.

The Law Enforcement Standards Laboratory (LESL) at the National Bureau of Standards, which develops voluntary national performance standards for compliance testing to ensure that individual items of equipment are suitable for use by criminal justice agencies. The standards are based upon laboratory testing and evaluation of representative samples of each item of equipment to determine the key attributes, develop test methods, and establish minimum performance requirements for each essential attribute. In addition to the highly technical standards, LESL also produces user guides that explain in nontechnical terms the capabilities of available equipment.

The Technology Assessment Program Information Center (TAPIC) operated by the International Association of Chiefs of Police (IACP), which supervises a national compliance testing program conducted by independent agencies. The standards developed by LESL serve as performance benchmarks against which commercial equipment is measured. The facilities, personnel, and testing capabilities of the independent laboratories are evaluated by LESL prior to testing each item of equipment, and LESL helps the Information Center staff review and analyze data. Test results are published in Consumer Product Reports designed to help justice system procurement officials make informed purchasing decisions.

All publications issued by the National Institute of Justice, including those of the Technology Assessment Program, are available from the National Criminal Justice Reference Service (NCJRS), which serves as a central information and reference source for the Nation's criminal justice community. For further information, or to register with NCJRS, write to the National Institute of Justice, National Criminal Justice Reference Service, Washington, DC 20531.

Paul Cascarano, Assistant Director National Institute of Justice 
NBSIR $81-2286$

THE CHARACTERIZATION OF AUTO

HEADLIGHT GLASS BY REFRACTIVE INDEX AND DENSITY

Prepared by the

Law Enforcement Standards Laboratory

National Engineering Laboratory

Washington, DC 20234

October 1981

Prepared for the

National Institute of Justice

U.S. Department of Justice

Washington, DC 20531

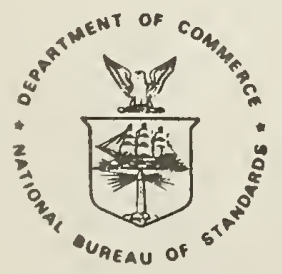

U.S. DEPARTMENT OF COMMERCE, Malcolm Baldrige, Secretary NATIONAL BUREAU OF STANDARDS, Ernest Ambler, Director 

This report was prepared by the Law Enforcement Standards Laboratory (LESL) of the National Bureau of Standards, under the direction of Robert $M$. Mills, former Program Manager for Investigative Aids, and Jacob J. Diamond and Lawrence K. Eliason, successive Chiefs of LESL. The document was revised by Paul H. Krupenie of LESL. Refractive index measurements were made by Irving Malitson, Marilyn $J$. Dodge, and Warren K. Gladden. Density measurements were made by Susan A. Mills. James A. Lechner did the statistical analysis for this paper. Henry $L$. Mason assisted in the drafting of the paper. Harold L. Steinberg collected the headlight samples and assisted in the coordination of the project. Michael Thomas cut the headlight glass into test pieces. The preparation of this document was sponsored by the National Institute of Justice, Lester D. Shubin, Standards Program Manager. 



\section{FOREWORD}

The Law Enforcement Standards Laboratory (LFSL) of the National Bureau of Standards (NBS) furnishes technical support to the National Institute of Justice (NIJ), formerly the National Institute of Law Enforcement and Criminal Justice, program to strengthen research that will assist law enforcement and criminal justice agencies in the selection and procurement of quality equipment.

LESL is: (1) Subjecting existing equipment to laboratory testing and evaluation, and (2) conducting research leading to the development of several series of documents, including national voluntary equipment standards, user guides, and technical reports.

This document is a law enforcement technology report developed by LESL under the sponsorship of NIJ as part of the Technology Assessment Program, which is described on the inside front cover of this report. Additional reports as well as other documents are being issued under the LESL program in the areas of protective equipment, communications equipment, security systems, weapons, emergency equipment, investigative aids, vehicles, and clothing.

Technical comments and suggestions concerning this report are invited from all interested parties. They may be addressed to the author or to the Law Enforcement Standards Laboratory, National Bureau of Standards, Washington, DC 20234.

Lawrence K. Eliason, Chief

Law Enforcement Standards Laboratory 

Foreword.

1. Summary

2. Glasses in Auto Headights

3. Testing Reliability of Evidence

4. Methods for Measuring Refractive Index

5. Refractive Index Measurements for this Study

6. Analysis of Refractive Index Data

6.1 Classification by subpopulation

6.2 Individualization .

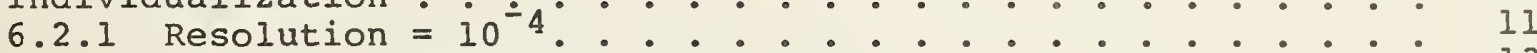

6.2 .1 .1 Calculation of $B . . . . . . . . . . . . .13$

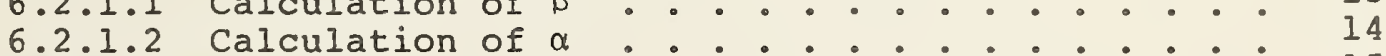

6.2 .2 Better Resolution . . . . . . . . . . . . . . . 15

6.3 Position Effect . . . . . . . . . . . . . . . . . . . . 20

6.4 Annealing . . . . . . . . . . . . . . . . . . . . . . . 21

6.5 Dispersion . . . . . . . . . . . . . . . . . . . . . . . . . . 2I

6.6 Temperature Coefficient of Refractive Index and Thermal Coefficient of Expansion . . . . . . . . . . . . . . 21

7. Density Measurements . . . . . . . . . . . . . . . . . . . 22

8. Analysis of Density Data . . . . . . . . . . . . . . . . . . 24

9. Conclusions and Update . . • . . • . . • . . . . . . . . . 25

Appendix A--"Trial by Mathematics" . • . . . . . . . . . . . . . . . 27

Appendix B--Allowance for Differences Between General Electric and Early Corning Lenses . . . . . . . . . . . . . . . 29

Appendix C--References . . . . . . . . . . . . . . . . . . . . . . 3I 



\title{
THE CHARACTERIZATION OF AUTO HFADLIGHT GLASS BY REFRACTIVE INDEX AND DENSITY
}

\author{
Law Enforcement Standards Laboratory \\ National Bureau of Standards \\ Washington, DC 20234
}

\section{SUMMARY}

By measurement of some physical property of headlight glass fragments found at the scene of an auto accident, forensic scientists have sometimes found it possible to infer that the glass was molded by a specific manufacturer. From an examination of the physical appearance of fragments it has sometimes been found possible to infer that the glass came from a broken headlight on a specific car. The glass used in auto headlights is now made by only two U.S. firms. The refractive index (RI) and density of the specimens are the most common parameters of interest to forensic scientists.

This study was designed to evaluate the potential usefulness of measurements of RI and/or density for forensic purposes. Automotive headlights were obtained from several sources. As of the time the analytic work was performed, 1 it appeared that there were three subpopulations of headlight glass: General Flectrif (GE), Corning manufactured before 1971, and Corning manufactured after 1971.2 The distributions of RI (and density) for the first two subpopulations overlapped considerably, so that one could not reliably determine to which of these a candidate piece of glass belonged. However, the latter population was different enough that one could reliably classify a fragment as belonging either to one of the first two or to the third. Furthermore, since headlights on the road at that time were about equally split between the three groups, the performance of both RI and density for individualization (i.e., the matching of an unknown fragment with a specific lens) was evaluated using the fact of an even split. Since the analytical work was done, the composition of glass has been changed several times by both manufacturers (and a significant number of lenses not made in the United States have appeared on the road). Without another comprehensive sampling of lenses, it is not possible to know how different the lenses on the road today really are. However, one may obtain a conservative figure by acting as though there is only one population, and this is done in section 9 (which updates the report to January 1981).

Certain conclusions remain valid with regard to individualization: 1) Measurement of density is likely to be more effective than measurement of RI: 2) the technique is capable of eliminating a large fraction of suspect lenses with only a small chance of rejecting the true match; 3) the technique is less satisfactory in confirming a true match; and 4) the effectiveness is not increased appreciably by taking more than a few repeated measurements, by annealing, the specimens, by measuring RI at several wavelengths, or by measuring both RI and density.

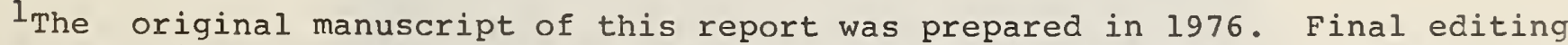
and publication was delayed as a consequence of personnel changes. The experimental techniques, methods of analysis, and data, although dated, combined with the present update provide a useful reference for the forensic science community.

2 The three subpopulations of headlight glass will be referred to in the text and tables as GE, early Corning, and late Corning, respectively. 
This report is divided as follows. Section 2 briefly describes the manufacture of headlamp qlass and the construction of a lamp. Section 3 discusses the reliability of using headliaht fragments as evidence and the two types of possible error. Section 4 describes RI measurement procedures, including references to earlier studies of headlamp glass. Section 5 describes the NBS procedure in more detail. Section 6 contains the bulk of the statistical analysis of the RI data, the analytical approach used, and. the conclusions reached (with a more detailed listing of its contents at the beqinning of the section). Section 7 discusses the NBS density measurement method, and section 8 presents an analysis of these measurements, comparing density and RI as individualizers. Section 9 has been added to update and summarize the results. Two short appendices and a list of references conclude the report.

\section{GLASSES IN AUTO HEADLIGHTS}

The sealed-beam headliqht generally used on automobiles in this country has a lens of borosilicate glass molded in one piece. Until recently only three firms were producing this glass--Corning Glass Works, General Electric Glass Works, and Anchor-Hocking Glass Co. In mid 1972 Anchor-Hocking discontinued production. In 1975 Corning produced about 60 percent of the total output, and General Flectric the remainder. In chemical composition, glasses made by these firms are believed to be quite similar, except that the Corning mix was modified in the fall of 1971 (see par. 2 of sec. 1).

Headlight glass is made by a continuous flow process in a very long tank furnace operating at about $1500^{\circ} \mathrm{C}$. Batches of raw materials are charged into the melting chamher. After melting, the viscous mass flows under a fireclay float and is continuously drawn off from the working end to be fed to forming machines which press it into the lens or reflector configurations needed. The process is apt to leave striations, bubbles, or bits of foreign material in the alass, so that the molded piece may well be nonuniform in its physical and optical properties. Figure 1 shows an example of striations in a headlight lens; the refractive index is evidently different from point to point.

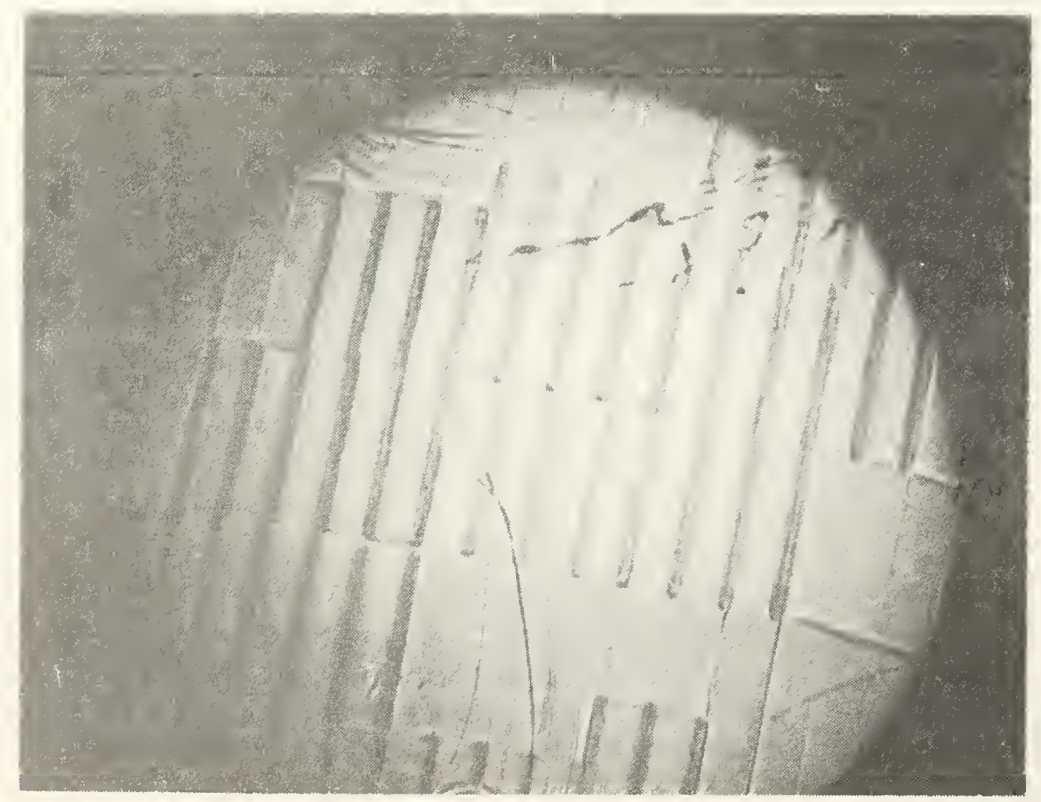

Figure 1. Striations in auto headlamp glass. 
After a lens and a reflector are fused together to form the sealed headlight, the assembly is given a minimal anneal by heating it to about $500^{\circ} \mathrm{C}$, to remove internal stress. However, an internal stress pattern may l, expected to result from the subsequent tempering process which conls the surface more rapidly than the interior of the material. A headiaht lens viewed through a polariscope (i.e.. with polarized light) would then show bright and dark areas indicative of the stress distribution and the variation of refractive index across the lens.

The standard reference material (SRM 1820), with refractive index certified for 13 wavelengths, has been produced iy the NBS for use by forensic scientists. Its RI varies from 1.48398 at $0.70652 \mu \mathrm{m}$ to 1.49994 at $0.40466 \mu \mathrm{m}$, with uncertainties within $5 \times 10^{-6}$. Its temperature coefficient of refractive index $\mathrm{dn} / \mathrm{dT}$ over a temperature range of $20-80^{\circ} \mathrm{C}$ is approximately $4.0 \times 10^{-6} /{ }^{\circ} \mathrm{C}$ at $0.58926 \mu \mathrm{m}$, the sodium $D_{1}, D_{2}$ line. Its density is $2.292+0.001$ $\mathrm{g} / \mathrm{cm}^{3}$ at $24^{\circ} \mathrm{C}, 50$ percent relative humidity, and a pressure of $99,442 \mathrm{pa}$ (746 $\mathrm{mm} \mathrm{Hg}$ ).

\section{TESTING RELIABILITY OF EVIDENCE}

The forensic scientist may be asked for a quantitative estimate of the reliability of statements characterizing a headlight glass offered as evidence. If the scientist can produce a photograph showing a perfect match between the fracture surfaces of a referral piece and a suspected broken lens, that is as close to absolute certainty as one can hope to come. However, measurements of physical properties--such as refractive index or density--are subject to uncertainties which are dependent on the property chosen for study, the instruments used, the number of readings taken, and the precision of those readings. If the data are adequate, the scientist may hope to individualize the specimen, i.e., to say with a stated deqree of confidence that a physical property measured for the referral piece will match (have the same value as) one and only one lens from the population of headlights on the road. Alternatively, the scientist may hope to classify the specimen, e.g., to say that it is not window glass, bottle qlass, or spectacle glass, and to say with a stated degree of confidence that one or more of its properties falls within the range that is representative of the headlight glass population.

In the report sections which follow, statistical techniques are applied to data actually taken at the NBS, and to hypothetical data which might result if some of the operative circumstances were changed. These techniques provide a performance test for forensic reliability. Measurements of reliability can be useful in three ways. First, they can be useful in determining the relative utility of various physical properties (e.g., refractive index and density) for making individualizations and classifications. Secondly, they can be useful in determining the relative merits of alternative methods for measuring these physical properties. And thirdly, they can be useful as one indication of the weight with which various types of physical evidence should be considered once introduced into courtroom testimony; that is, physical evidence which has a greater degree of uncertainty associated with it probably should not enjoy as much weight as does a more reliable type of physical evidence.

In addition to reliability, there are other performance attributes (e.g., the time required to make the analysis, the cost of the procedure, and the degree of preservation of destructible evidence) which are important to forensic scientists. However, these other attributes were not within the scope of this study.

Since many of the techniques in this report are statistical in nature, it is prudent to acknowledge the concern of some legal authorities concerning the use of statistical methods in the trial process. Appendix $A$, quoting 
from the published literature, supports the appropriateness of the kind of statistical investigation reported in this paper.

For classification according to manufacturer to be reliable, the distribution of values of some lens property--such as refractive index or density--must not overlap among lenses molded by different manufacturers. For individualization to be reliable, the distribution-width (i.e., standard deviation) of property values within any one lens must be small in comparison with the distribution-width of property values among all headlights on the road. Otherwise, there would be no discriminatory power.

The hypothesis that two glass fragments are from the same headlight is subject to two possible kinds of error; a nonmatch may be declared when a match actually exists (known as false rejection), and a match may be declared when it does not actually exist (known as a false match). The probability of a false rejection is denoted by $\alpha$, and the probability of a false match lor false acceptance) by $\beta$.

In aeneral, probabilities can be computed by calculating the area under a section of the appropriate normalized frequency-distribution curve. Clearly . it is important to select the correct section from the correct distribution. To compute $\alpha$, the distribution of interest represents the property values found within any individual lens, as shown in figure 2. The section representing the a-error probability is the area under this frequencydistribution curve which is outside the range of "matching" property values, i.e., outside the shaded band in figure 2 .

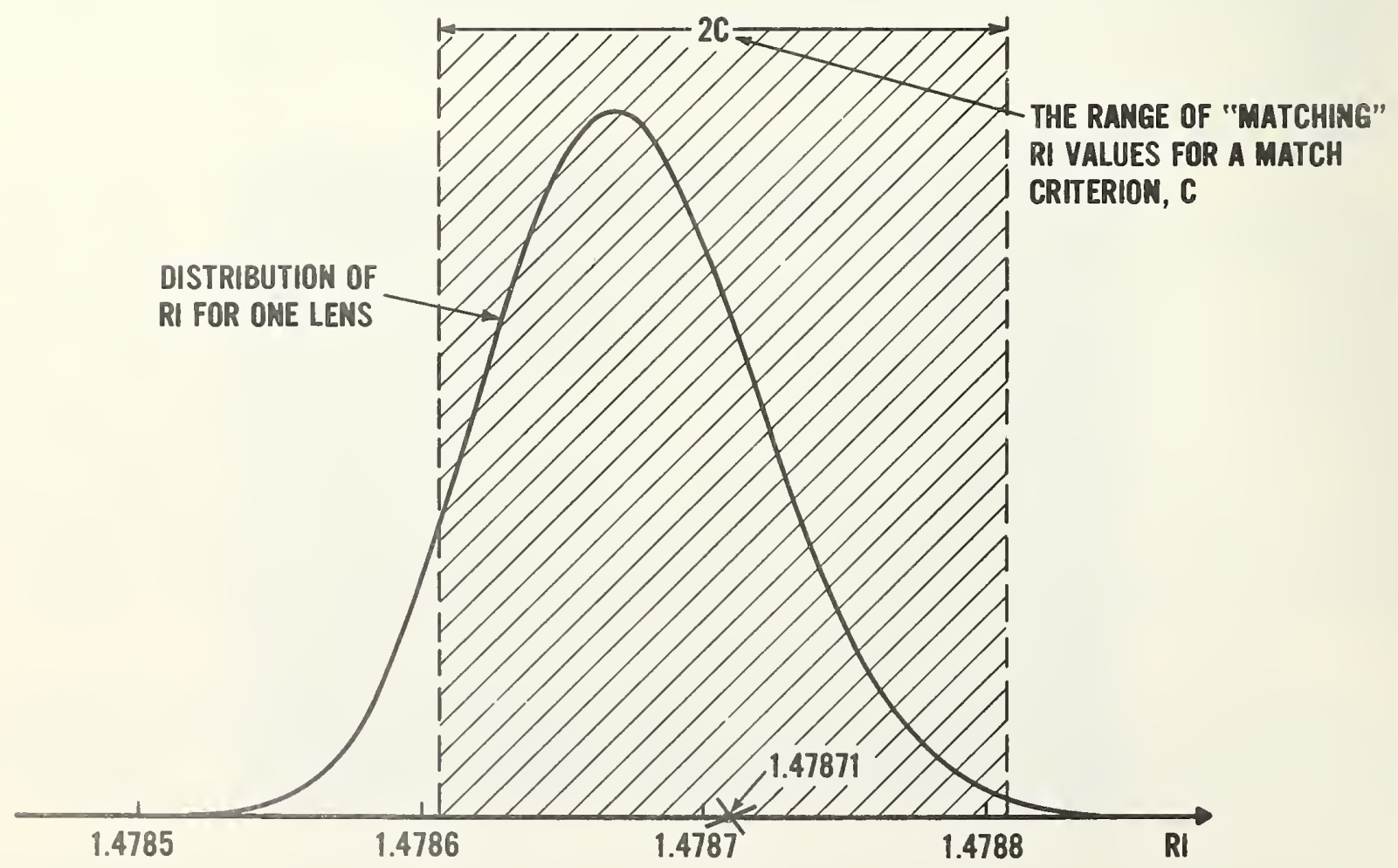

Figure 2. Illustration of a-error. 
The referral piece may have any value of RI within this population range, but is more likely to have a value near the center of the range (the "lens: mean"). An " $x$ " appears in figure 2 somewhat off center to indicate a possible value for this referral RI. Another piece will be said to match this referral piece if its measured RI is sufficiently close to the referral RI. The range of "matching" RI values for a hypothetical match criterion is shown in figure 2 as a shaded band. AnY RI values outside the shaded area will erroneously be declared "nonmatching." The area outside the shaded band, representing the a-error, depends on the width of the band which is twice the criterion value $c$; it also depends on the position of the " $x$ " in figure 2 relative to the lens mean.

On the other hand, for $\beta$, interest centers on the distribution of the property across the remainder of the appropriate lens subpopulation, as shown in figure 3. The area of interest is the area under this frequencydistribution curve which is within the shaded band. Here too, an " $x$ " indicates the RI of the referral fragment. But with the scale chanoed to accommodate the much larger spread of R.I values across the population, the shaded area appears as a very narrow slice out of the population. Only the small fraction of the population which is within the shaded area would, if selected, be declared (falsely) matching. Thus $\beta$, the probability of a false match, is given by the area under the probability curve within the shaded reqion. Again, it matters where the referral fragment falls with respect to the population mean; an average $\beta$ is therefore calculated.

For measurements made in the field, the uncertainties resulting from inadequate equipment or lack of operative skill are likely to be greater than those made under ideal laboratory conditions such as those reported herein. Thus, values of $\alpha$ and $\beta$ based on data taken at the NBS will be "best case" results; the probability of error corresponding to actual investigative situations will be no less than that reported here, and may be greater.

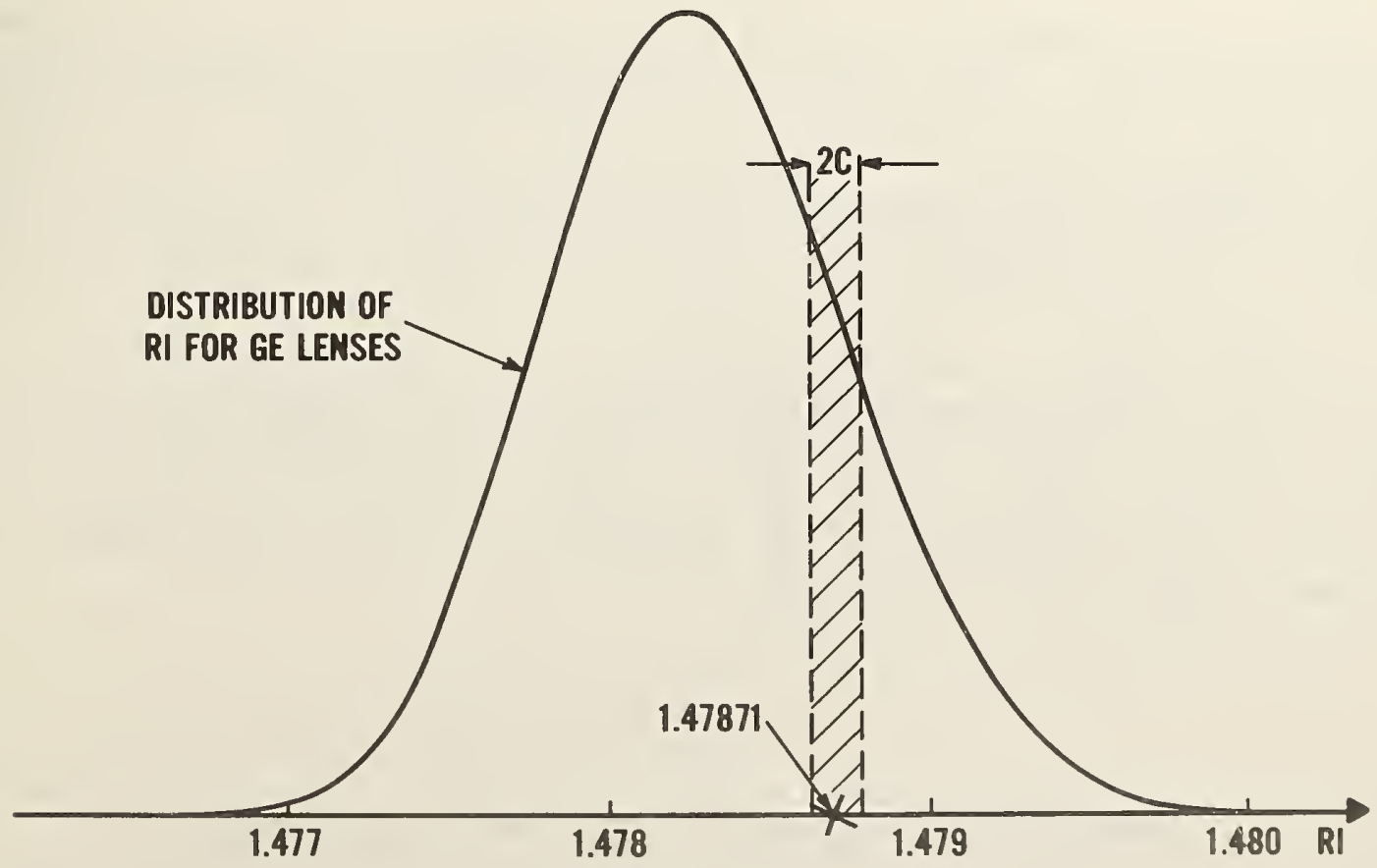

Figure 3. Illustration of $\beta$-error. 


\section{METHODS FOR MEASURING REFRACTIVE INDEX}

Refractive index is defined as the ratio, $n$, of the velocity of light in air to its velocity in a transparent medium. Generally measurements are made with monochromatic light. Measurements of $R I$ may be made by any one of several methods. These fall into two general classes: (a) measurement of the change of angle suffered by a light ray as it passes through a geometrically regular sample, and (b) observation of a (possibly) irregular fragment while immersed in a liquid of known RI. The first class is used for precise measurements. It requires a refractometer. An Abbe refractometer was used by Greene and Burd [1] 3 in 1949 in measuring the RI of glass from 50 headlamps, with a claimed accuracy of $+1 \times 10^{-4}$. The RI of these glasses ranged from 1.5072 to 1.5101 , which is substantially higher than the RI of glass made more recently.

The second class requires a transparent container which can be mounted on a microscope stage. In the simple Becke line method [2] the test fragment is immersed in one or another of a series of liquids graded in RI and observed through a microscope with systematic reduction of illumination. If the fragment has an RI slightly lower or slightly higher than that of the liquid, and the focusing depth of the microscope is changed slightly, a bright line will appear at an edge of the specimen. When a liquid is found that renders the fragment invisible, the RI of the solid is known to be the same as that of the liquid. Under favorable conditions, readings can be made to $5 \times 10^{-4}$, according to Allen [2].

A comparative study of methods of illuminating the immersed specimen was made by Saylor [3]. He compared central illumination, as used by Becke, with oblique illumination and with a double-diaphragm method. His tests on crushed borosilicate glass showed that a matching of indices could be obtained with much better consistency using the double diaphragm and a lowpower objective. This technique yielded an average error of $2 \times 10^{-5}$ with a maximum error of $5 \times 10^{-5}$ for RI of macro-specimens in work by Faick and Foronoff [4].

Use of a single immersion liquid whose temperature can be increased at a slow regular rate on a "hot stage" is an alternative to a graded series of RI liquids. This method was used by Dabbs and Pearson [5] and by Dixon [6]. Ojena and DeForest $[7,8]$ added the use of phase microscopy, and found the internal variation within a lens to be about $6 \times 10^{-5}$. The overall range for 1970 headlamp glass was 1.47713 to 1.47934 with a claimed standard deviation of $3.4 \times 10^{-5}$. They concluded that "the bulk of these variations could not have been measured with the simple Becke line technique (accuracy +0.001)."

The F, D, and C lines were used by McCrone [9] for observation of the Becke line with specimens on a heated stage. His collaborative study [10]. adopted as an interim official first action by the Association of official Analytical chemists $(A O A C)$, reported an overall laboratory average error of $33 \times 10^{-5}$ in their results on two standard specimens. The technique uses a liquid with RI exceeding that of the specimen at all wavelengths; precise data on the liquid $\mathrm{dn} / \mathrm{dT}$ is required.

3 Numbers in brackets refer to references appearing in appendix $C$. 


\section{REFRACTIVE INDEX MEASUREMENTS FOR TIIS STUDY}

For the NBS study, the 71 headlights were obtained from sources listed in table 1. The fused joint between a lens and its reflector was ground away, and the lens was cut into 13 pieces (as shown in fig. 4) with a diamond-faced saw. This provided a total of 923 specimens. The four edges of each piece were smoothed on a surface grinder, and each of its $90^{\circ}$-corners was assiqned a number from one to four, as shown in the figure.

Conceptually, the internal stresses within headiight lenses could be relieved to a different degree, depending on whether a lens is cut up using the diamond-faced saw, or smashed as in an actual vehicle collision. If difference existed, our RI data would not be representative of RI values encountered by law enforcement investigators. To check this, two lenses were smashed, and the resulting pieces were then cut into regular shapes. Comparing these pieces with those cut from the figure 4 pattern, no significant differences were found in either average RI values or within-lens RI variation.

Measurements of RI were made on about 600 rectangles using a precision vee-block refractometer capable of readings to within $2 \times 10^{-5}$ for glass of optical qualjty. The test corner of the rectangle was fitted into the $90^{\circ}$ vee-block as shown in figure 5. The test sample was sealed to the vee-block with a contact liquid of similar RI, in this case a mixture of ethylene qlycol and benzyl alcohol. An important feature of this method is that the average index through the body of the test piece is measured, not just the surface value. The latter value is what is observed with the grazing incidence method using an Abbe refractometer. Readings were taken on one or more corners of each rectangle by four different observers on different occasions. Each RI value reported was the average of five, computed from measurements of the angle between the successive emergent rays. All readings were made at a controlled room temperature near $20^{\circ} \mathrm{C}$.

Table 1. Sources of headight glass for NBS study

General Flectric

Early Corning

Late Corning

$\begin{array}{llc}9^{\mathrm{a}} & 7^{\mathrm{a}} & 12^{\mathrm{a}} \\ 7^{\mathrm{b}} & 8^{\mathrm{b}} & 3^{\mathrm{b}} \\ & 5^{\mathrm{a}} & 20^{\mathrm{c}}\end{array}$

a purchased new in 1973-74.

b Used between 1965 and 1973 by NBS colleagues.

${ }^{c}$ Production line on four days in April 1974.

d production line. 


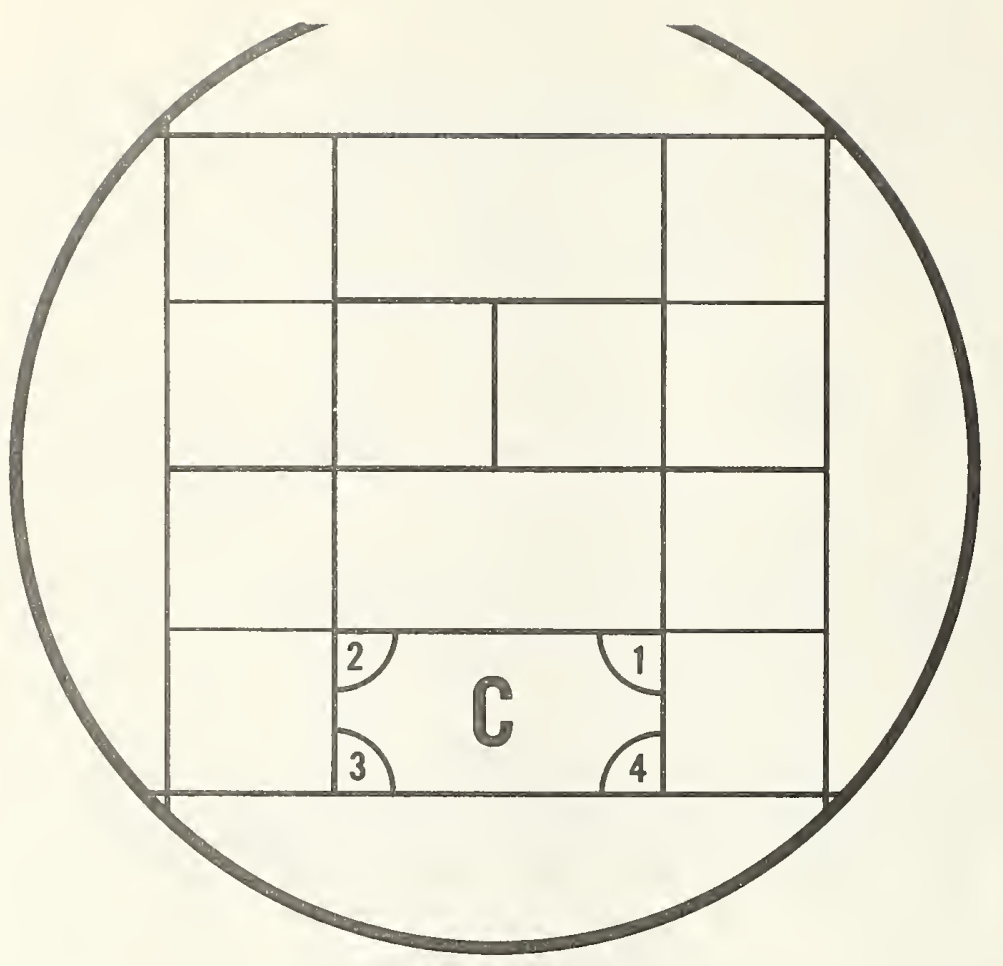

Figure 4. Lens cuts for NBS study.

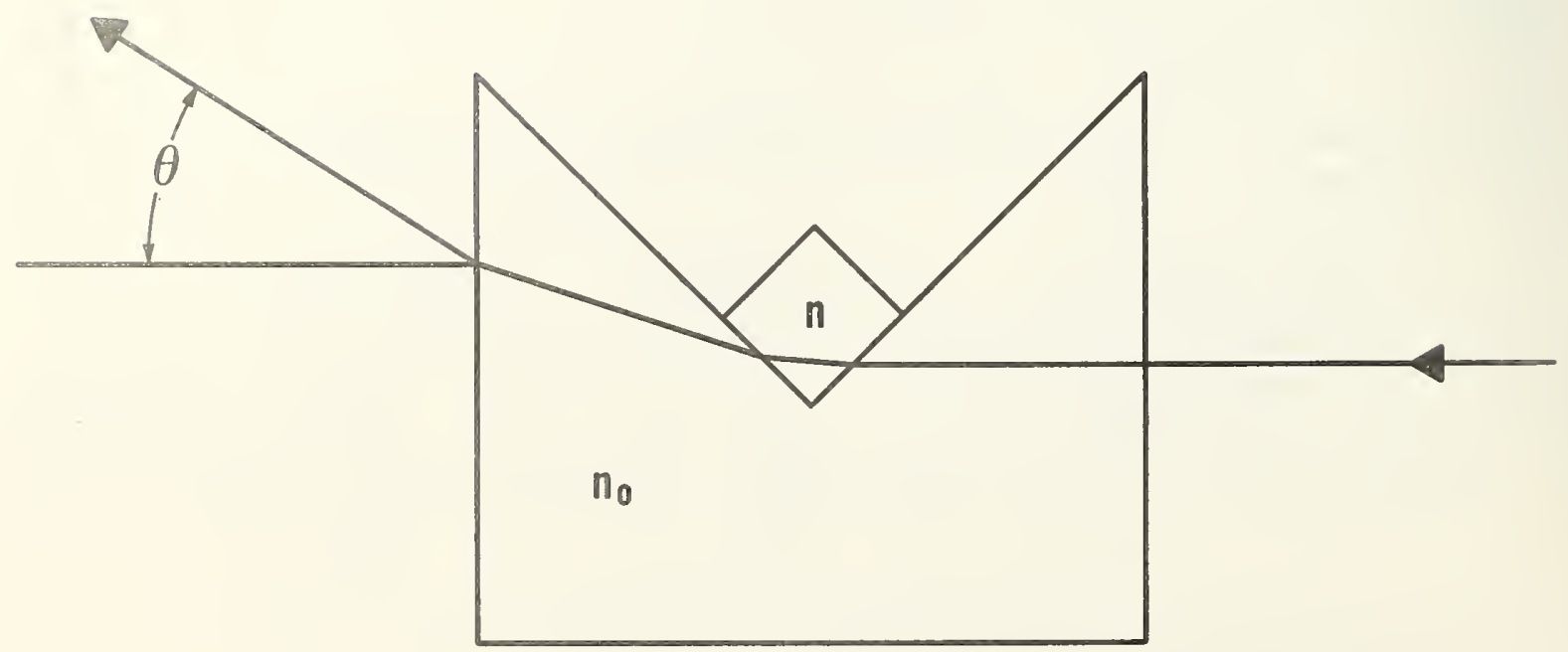

Figure 5. Schematic representation of Vee-block refractometer:

$\mathrm{n}_{\mathrm{O}}=\mathrm{RI}$ of reference prism (Vee-Block); $\mathrm{n}=\mathrm{RI}$ of glass sample;

$\theta=$ angular deviation of light beam. The following expression holds:

$$
n=\left[n_{0}^{2}+\sin \theta\left(n^{2}-\sin \theta\right)^{1 / 2}\right]^{1 / 2}
$$




\section{ANALYSIS OF REFRACTIVF, INDEX DATA}

This section is subdivided as follows: section 6.1 considers Ll" classification of a piece of headlamp glass--i.e., the determination of which of the three subpopulations it belongs to. Section 6.2 covers individualization to the specific lens from which the piece originated--with coarse measurements considered in section 6.2.1, and finer measurements in section 6.2.2. Miscellaneous questions are covered in the remainder of the section: whether RI varies consistently with position within a lens, in 6.3 ; effects of annealing, 6.4; dispersion, 6.5; and temperature effects, 6.6 .

\subsection{Classification by Subpopulation}

Measurements of RI on 71 lenses indicated that there are three subpopulations to be considered as shown graphically in figure 6 and listed in table 2 (for the sodium $D_{1}, D_{2}$ doublet). As mentioned in section 3 , the reliability of classifications hinges on the degree of overlap of the various subpopulations of auto headlights on the road. Since the 25 lenses obtained directly from production lines (see table 1 ) were manufactured within very short periods of time, they would be expected to be (and in fact were found to be) considerably more alike than other lenses. The use of these lenses in the analyses to follow would distort the results, so they were not used, and are not represented in the data summarized in table 2 .

The table is based on an average RI value for each lens, which is in turn hased on five readings at each of about 13 locations on that lens. Thus each lens contributed one $x$-value. The average of these 15 or 16 values, denoted by $\bar{x}$, and the group standard deviation, denoted by $s$, are estimates of the mean and standard deviation of the population of possible lens-averages for the aiven group. The range given is the range of the 15 or 16 -values. Finally, the confidence limits which have been computed for the median of the population are valid regardless of the shape of that population distribution. The meaning of the confidence coefficient is as follows (taking the GF column as an example): In at least 96 percent of the (independent) cases where a confidence interval is calculated in the manner used here, that confidence interval will bracket the true median.
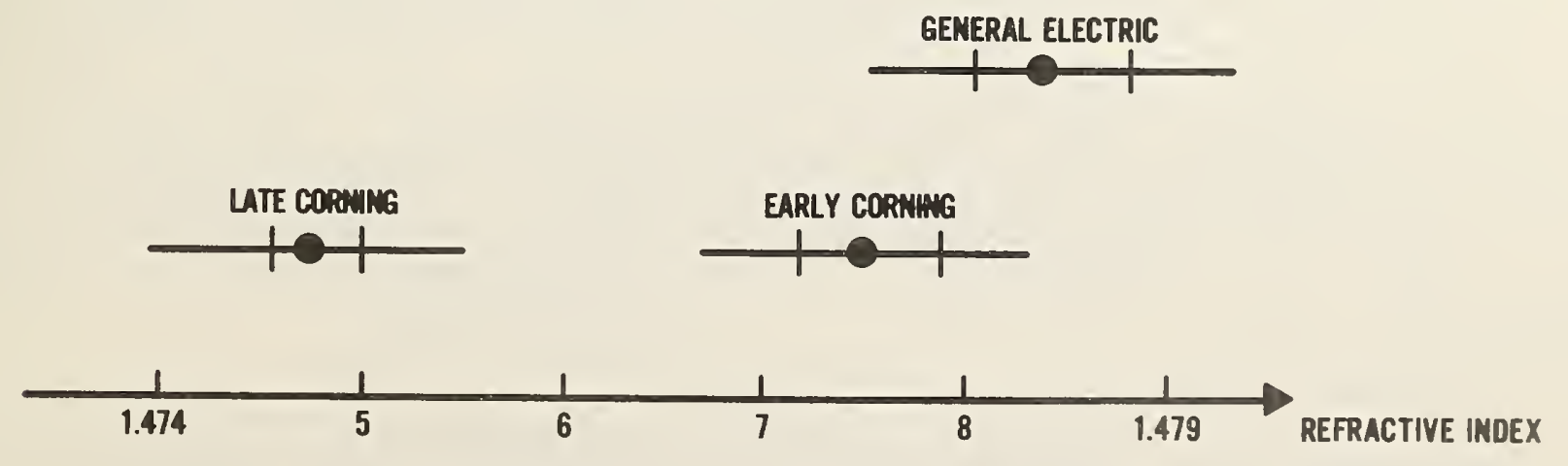

Figure 6. Measured refractive index values for different groups of headlamp lenses. Each bar indicates the spread of lens averages for the aroup: the vertical ticks indicate the confidence limits for the medians of the underlying populations; and the heavy dots indicate the average of all measured lenses in the group. (See also table 1.) 
Table 2. Refractive indexes of automotive headlights

\begin{tabular}{|c|c|c|c|}
\hline $\begin{array}{l}\text { Population } \\
\text { statistics }\end{array}$ & $\begin{array}{l}\text { General } \\
\text { Electric }\end{array}$ & $\begin{array}{l}\text { Corning, } \\
\text { before } \\
11 / 1971\end{array}$ & $\begin{array}{l}\text { Corning, } \\
\text { after } \\
11 / 1971\end{array}$ \\
\hline Number of lenses & 15 & 16 & 15 \\
\hline $\begin{array}{l}\bar{X} \text { (average }^{a} \text { RI for } \\
\text { all lenses) }\end{array}$ & 1.47835 & 1.47749 & 1.47476 \\
\hline $\begin{array}{l}\text { s (estimate of std. } \\
\text { dev. within } \\
\text { subpopulation) }\end{array}$ & 0.00051 & 0.00046 & 0.00030 \\
\hline $\begin{array}{l}\text { Range (of lens } \\
\text { averages) }\end{array}$ & $\begin{array}{l}1.47743 \text { to } \\
1.47899\end{array}$ & $\begin{array}{l}1.47697 \text { to } \\
1.47837\end{array}$ & $\begin{array}{l}1.47430 \text { to } \\
1.47528\end{array}$ \\
\hline $\begin{array}{l}\text { Confidence limits } \\
\text { for the median }\end{array}$ & $\begin{array}{l}1.47801 \text { and } \\
1.47875\end{array}$ & $\begin{array}{l}1.47720 \text { and } \\
1.47787\end{array}$ & $\begin{array}{l}1.47456 \text { and } \\
1.47497\end{array}$ \\
\hline $\begin{array}{l}\text { Confidence } \\
\text { coefficient }\end{array}$ & .96 & .98 & .96 \\
\hline
\end{tabular}

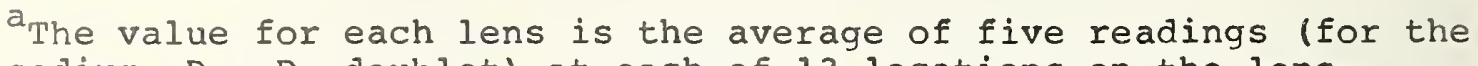
sodium $D_{1}, D_{2}$ doublet) at each of 13 locations on the lens.

The results show that the average RI of each subpopulation of lenses (GE, early Corning, and late Corning) differs significantly from the other two in the third decimal place. The difference between late corning and the other two is about $3 \times 10^{-3}$. Since this difference is many times larger than the standard deviations found within the subpopulations, late Corning glass should be distinguishable, even by the simple Becke line method often used in crime laboratories for RI determinations. However, a piece of glass from one of the other two groups cannot be assigned unambiguously to either one of the two, because the distributions of RI values for those two groups overlap considerably (see fig. 6).

\subsection{Individualization}

Individualization involves being able to show that the variability of RI within a lens is small compared with the variability among lenses on the road. The data used to compute table 2 cover all three manufacturers and a representative range of manufacturing dates. For 46 of these lenses, one at a time, the standard deviation was calculated for the set of RI values measured for the different rectangles. These 46 standard deviations were combined to give an estimate of $6.8 \times 10^{-5}$ for $\sigma \mathrm{L}$, the standard deviation for a measurement made at a random point on a lens. (The $95 \%$ confidence limits for $\sigma_{L}$ are $6.3 \times 10^{-5}$ and $7.3 \times 10^{-5}$ ). From table 2, the estimates of $\sigma_{p}$, the standard deviation of RI values across a given subpopulation, range between $30 \times 10^{-5}$ and $51 \times 10^{-5}$. 
The standard deviation across a lens, $\sigma_{L}$, results from two sources of variation--the measurement process $\left(\sigma_{m}\right)$, and the inhomogeneity of RI within the lens $\left(\sigma_{i}\right)$. The measurement component can be estimated from repeated readings on individual corners. A total of 89 pairs of such readings were made by one operator from eight representative lenses, yielding an estimate of $3.8 \times 10^{-5}$ for the standard deviation attributable to measurement error. Thus, the estimated standard deviation due to the inhomogeneity of RI within the lens is $5.6 \times 10^{-5}$, i.e., $\left[(6.8)^{2}-(3.8)^{2} \simeq(5.6)^{2}\right]$. This indicates that it would not be reasonable to expect any method of RI measurement to achieve a standard deviation, for measurements across a lens, of less than about $6 \times 10^{-5}$ for a glass as inhomogeneous as that used in headlamp lenses. For convenience the estimated values of the various standard deviations are tabulated in table 3 .

There is no significant evidence of non-Normality for any of the three subpopulations, nor for the values within a single lens. Therefore, throughout the remainder of this report, calculations are based on a Normal (Gaussian) distribution of RI values for each of the three subpopulations, with the standard deviation $\sigma_{\mathrm{p}}$ different for each subpopulation.

A Normal distribution is also assumed for the RI values within an individual lens, with standard deviation $\sigma_{i}$ which does not depend on the subpopulation.

\section{2 .1 Resolution $=10^{-4}$}

The RI measurements at NBS were made by experienced observers using a refractometer under optimum laboratory conditions. RI measurements in the field are likely to be made to only $1 \times 10^{-3}$, or perhaps $1 \times 10^{-4}$. When the reading scale is this coarse, how large are the error probabilities, $\alpha$ and $B$ ?

Table 3. Estimated standard deviations for refractive index

Symbol Type of variability Estimated value

\begin{tabular}{|c|c|c|}
\hline${ }^{\sigma} \mathrm{L}$ & $\begin{array}{l}\text { Measurements at } \\
\text { random positions } \\
\text { across a lens }\end{array}$ & $6.8 \times 10^{-5}$ \\
\hline$\sigma_{i}$ & Inhomogeneity in a lens & $5.6 \times 10^{-5}$ \\
\hline${ }^{\sigma} \mathrm{m}$ & $\begin{array}{l}\text { Due to the NBS } \\
\text { measurement process }\end{array}$ & $3.8 \times 10^{-5}$ \\
\hline$\sigma_{1}$ & $\begin{array}{l}\text { Among late Corning } \\
\text { lenses on the road }\end{array}$ & $30 \times 10^{-5}$ \\
\hline$\sigma_{2}$ & $\begin{array}{l}\text { Among } \mathrm{GE} \text { and early } \\
\text { Corning lenses on } \\
\text { the road }\end{array}$ & $\begin{array}{l}\text { Average of } 51 \times 10^{-5} \text { and } \\
46 \times 10^{-5}=48 \times 10^{-5}\end{array}$ \\
\hline
\end{tabular}


Suppose that readings are taken with no measurement error on a scale of uniformly-spaced values with interval $\theta=1 \times 10^{-4}$. Since actual measurements are not perfectly accurate, and since many laboratories have a measurement resolution which is closer to $10^{-3}$ rather than $10^{-4}$, an optimistic case is being considered here.

The results are given in table 4. The remainder of section 6.2.1 contains the statistical derivations and calculations which produce table 4, and may be skipped by readers so inclined without interfering with the remainder of the report.

It has been assumed that the true RI values across any one lens constitute a Normal population, with mean values varying from lens to lens, and with a standard deviation independent of which subpopulation is being considered. Since $\sigma_{i}$ is relatively small compared to the subpopulation standard deviation, $\sigma_{P}$, the position of the mean for a given lens can be thought of as uniformly distributed over the interval between some two adjacent readout values.

Denote readout RI values by $x$, and true RI values by $y$. Any sensible rule for deciding whether a referral fragment matches a sample from the population must be of the following form: If $\mathrm{x}_{1}$ is the readout value for the referral fraqment, and $x_{2}$ is a readout value for some suspected source lens in the population, a match is declared when and only when $\left|x_{1}-x_{2}\right|$ is at most $k \theta$. We are free to choose the integer $\mathrm{k}$.

It is easy to see that $k=0$ will not be very satisfactory, because if the true mean $R I$ value, $\bar{Y}$, is midway between two readout values, the probability is approximately 0.5 that two samples from that lens will give different readout values. False rejection would be declared about 50 percent of the time. $\alpha$ has also been found to be about 50 percent for other values of $\bar{y}$ when $k=0$. The larger we make $k$, the smaller will be $\alpha$, the probability for a false rejection, and the larger will be $B$, the probability for a false match.

Table 4. Reliability of headlight glass individualization--low resolution RI measurements

Assumptions (both optimistic)

1. No measurement errors

2. Resolution of measurements, $\theta=1 \times 10^{-4}$

A match is declared if $\left|x_{1}-x_{2}\right| \leq k \theta$

\begin{tabular}{lcc}
$k$ & $\begin{array}{c}\text { Average } \\
\alpha\end{array}$ & $\begin{array}{c}\text { Weighted average } \\
\text { of } B\end{array}$ \\
\hline 0 & 0.56 & 0.037 \\
1 & 0.078 & 0.11 \\
2 & 0.0031 & 0.17
\end{tabular}




\subsubsection{Calculation of $\beta$}

Under the optimistic assumption of no measurement errors, $x_{1}$ will be the nearest possible readout value to $y_{1} ; x_{1}$ and $y_{1}$ can differ by no more than $\theta / 2$. The same holds for $x_{2}$ and $y_{2}$.

If $x_{2}$ is to be within $k \theta$ of $x_{1}--$ and thereby be a false match-- $y_{2}$ must be between $x_{1}-(k+1 / 2) \theta$ and $x_{1}+(k+1 / 2) \theta$. For a lens randomly drawn from the population of lenses on the road, the chance that $y_{2}$ is within this interval depends on where the interval lies with respect to the mean up of the subpopulation, $i . e .$, on the difference $x_{1}-\mu_{p}$. This probability is maximized when that difference is zero. Denote this maximum value by $B *$. It is the area under the Normal distribution $\left(\mu_{p}=x_{1}, \sigma=\sigma_{p}\right)$ bounded by $x_{1}-(k+1 / 2) \theta$ and $x_{1}+(k+1 / 2) \theta:$

$$
B *=\Phi\left[(k+1 / 2) \theta / \sigma_{p}\right]-\Phi\left[-(k+1 / 2) \theta / \sigma_{p}\right]
$$

where $\phi$ is the integral of $(2 \pi)^{-1 / 2} \exp \left(-t^{2} / 2\right)$ from $-\infty$ to the argument within the brackets. In the above case, the central area of interest is symmetrical about the distribution mean, and can be written as:

$$
B *=2 \Phi\left[(k+1 / 2) \theta / \sigma_{p}\right]-1
$$

Since the average height of a Normal distribution is $1 / \sqrt{2}$ times the maximum height (at the mean), multiply $\beta^{*}$ by $1 / \sqrt{2}$ to allow for $x_{1}-$ values different from the mean.

Account must also be taken of the fact that there are three subpopulations of lens glass: late Corning, early Corning, and GE. We will denote the $B$ corresponding to the late Corning subpopulation by $\beta_{1}$, and the $\beta$ corresponding to the early Corning and GE subpopulations by $B_{2}$.

Assume, for example, that each of the three contains a third of all lenses on the road. If the referral fragment happens to be from a late Corning lens, only one-third of all the other lenses on the road will have a chance of false acceptance. Thus:

$$
B_{1}=B_{1} * /(3 \sqrt{2}) .
$$

Or, if the referral fragment happens to be from an early Corning or GE lens, only two-thirds of all the other lenses on the road will have a chance of false acceptance so that:

$$
B_{2}=2 B_{2} * /(3 \sqrt{2}) \text {. }
$$

The first situation will occur about one-third of the time, the second about two-thirds of the time. Thus for the entire population the average is:

$$
\begin{gathered}
B=\frac{1}{3} B_{1}+\frac{2}{3} B_{2} \\
B=\left(\frac{1}{3}\right)\left(\frac{1}{3}\right)\left(B_{1} * / \sqrt{2}\right)+\left(\frac{2}{3}\right)\left(\frac{2}{3}\right)\left(B_{2} * / \sqrt{2}\right) .
\end{gathered}
$$


For the late Corning subpopulation, with $\theta=1 \times 10^{-4}, \sigma_{p}=\sigma_{1}=3 \times 10^{-4}$, and $k=1$,

$$
\Phi\left[\frac{3}{2}\left(\frac{1}{3}\right)\right]=\Phi[0.5]=0.6915 ;
$$

thus

$$
\beta_{1}=\frac{1}{3 \sqrt{2}}[2(0.6915)-1]=0.0903
$$

For the other subpopulation, ${ }_{0}{ }_{\mathrm{p}}=\sigma_{2}=4.8 \times 10^{-4}$;

$$
\Phi\left[\frac{3}{2(4.8)}\right]=\Phi[0.3125]=0.6227
$$

and

$$
B_{2}=\frac{2}{3 \sqrt{2}}[2(0.6227)-1]=0.1157
$$

The weighted average $B$ (i.e., the chance of a false match) for $k=1, \theta=1 \times 10^{-4}$, and no measurement error is thus:

$$
B=0.1072 .4
$$

\section{2 .1 .2 Calculation of $\alpha$}

To determine $\alpha$ with the same assumptions for $\theta, \sigma_{p}$, and $k$, suppose that the two pieces of glass to be compared are from the same lens. Denote by $x_{1}$ a readout value on the referral fragment, and by $Y_{1}$ the true (but unknown) RI value for that fragment. Since we are assuming $x_{1}$ to be the nearest possible readout value to $y_{1}, x_{1}$ and $y_{1}$ cannot differ by more than $\theta / 2$. At the other extreme, $y_{1}$ might exactly coincide with a readout value. We will calculate $\alpha$ for each of these extreme cases. Suppose $y_{2}$ is the true RI value for the other fragment. Then $y_{2}-y_{1}$ will have a Normal distribution with mean zero and standard deviation $\sqrt{2} \sigma_{1}$. If $y_{1}=x_{1}$, the probability that another $x_{2}$ will differ from $x_{1}$ by more than $k \theta$ is the probability that $Y_{2}$ will differ from $Y_{1}$ by more than $(k+1 / 2) \theta$, i.e., :

$$
a_{a}=2 \Phi\left[-(k+1 / 2) \theta /\left(\sigma_{i} \sqrt{2}\right)\right] \text {. }
$$

For $k=1$,

$$
\alpha_{a}=2 \Phi[-1.89401]=0.0582
$$

However, if $y_{1}=x_{1}+\theta / 2$, the probability that another $x_{2}$ will differ from $x_{1}$ by more than $k \theta$ is the probability that $y_{2}$ will be greater than $y_{1}+k \theta$ or less than $y_{1}-(k+1) \theta$, i.e.,

${ }^{4}$ By expanding the model (and complicating the derivation) to account for the difference between GE and early Corning, this value can be further reduced, to about .086 . Details are in appendix $B$. 


$$
\alpha_{b}=\Phi\left[-k \theta /\left(\sigma_{i} \sqrt{2)}\right]+\Phi\left[-(k+1) \theta /\left(\sigma_{i} \sqrt{2)}\right]\right.\right.
$$

Again for $k=1$,

$$
\begin{aligned}
\alpha_{b} & =\Phi[-1.2627]+\Phi[-2.5254] \\
& =0.1034+0.0058=0.1092 .
\end{aligned}
$$

In fact, $\alpha$ was calculated also for other intermediate cases, because the dependence of $\alpha$ on $y_{1}-x_{1}$ is not smooth. The result was (for $k=1$ ):

$$
\alpha=0.078 \text {. }
$$

These results for $k=1$ and similar ones for $k=0$ and $k=2$ are tabulated in table 4, and plotted in figure 7 as three points. It should be remembered that these results were obtained using two optimistic assumptions; realistic measurement errors and measurement resolution of $\theta>1 \times 10^{-4}$ will degrade this performance.

\subsubsection{Better Resolution}

Suppose that more precise RI data are obtained. It will be shown in this section that under certain conditions, slightly improved values for $\alpha$ and $\beta$ can be obtained. These results are presented in figure 7 and tables $5 a-5 d$. Whether the improved reliability is worth the added cost and time is a question forensic scientists will have to answer. Readers not interested in the statistical derivations can refer to. the figure and tables, and then skip to section 6.3 without loss of continuity.

Assume that $R I$ data is taken to five decimal places with the standard deviation due to the measurement process, $\sigma_{m}$, equaling $3.8 \times 10^{-5}$. The standard deviation corresponding to the inherent variability within a headlight, $\sigma_{i}$, is $5.6 \times 10^{-5}$, as before (see table 3).

If a match is to be declared correctly, then referral fragment and suspected source must actually be pieces from a single lens. In such a situation, let:

$$
\begin{aligned}
& \mathrm{m}_{\mathrm{r}}=\text { number of locations measured on the referral fragment, } \\
& \mathrm{m}_{\mathrm{S}}=\text { number of locations measured on the suspected source, } \\
& \mathrm{n}_{\mathrm{r}}=\text { number of independent measurements at each point of the referral } \\
& \text { fragment, } \\
& \mathrm{n}_{\mathrm{S}}=\text { number of independent measurements at each point of the } \\
& \text { suspected source, and } \\
& \sigma_{D}=\text { standard deviation of the difference }\left|\bar{x}_{1}-\bar{x}_{2}\right| \text { of RI values for } \\
& \text { two sets of measurements on one lens; that difference will } \\
& \text { be normally distributed with a mean of zero. }
\end{aligned}
$$

Then

$$
\sigma_{D}^{2}=\left(\frac{1}{m_{r}}+\frac{1}{m_{s}}\right) \sigma_{i}{ }^{2}+\left(\frac{1}{m_{r} n_{r}}+\frac{1}{m_{s} n_{s}}\right) \sigma_{m}^{2} .
$$




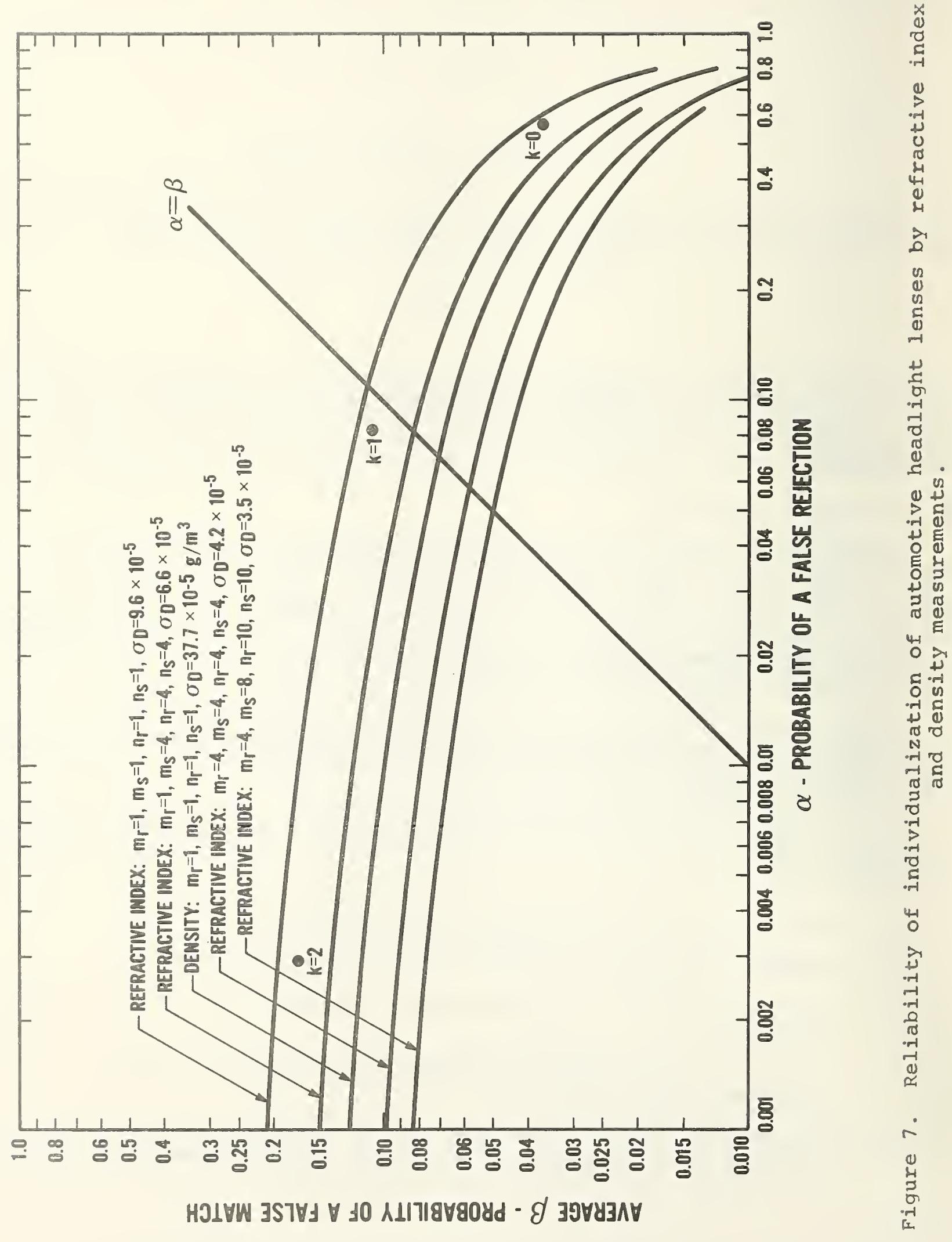


One location of referral piece measured one time. One location of suspect piece measured one time.

$$
\sigma_{D}=9.57 \times 10^{-5}
$$

\begin{tabular}{lllll}
\hline$a$ & $C \times 10^{5}$ & \multicolumn{1}{c}{$\beta_{1}$} & $\beta_{2}$ & $\beta$ \\
\hline 0.001 & 31.5 & 0.166 & 0.230 & 0.209 \\
0.004 & 27.6 & 0.151 & 0.205 & 0.187 \\
0.008 & 25.4 & 0.142 & 0.190 & 0.174 \\
0.010 & 24.7 & 0.139 & 0.185 & 0.170 \\
0.020 & 22.3 & 0.128 & 0.168 & 0.155 \\
0.040 & 19.7 & 0.115 & 0.150 & 0.138 \\
0.050 & 18.8 & 0.110 & 0.143 & 0.132 \\
0.060 & 18.0 & 0.106 & 0.138 & 0.127 \\
0.080 & 16.8 & 0.100 & 0.129 & 0.119 \\
0.10 & 15.7 & 0.0944 & 0.121 & 0.112 \\
0.20 & 12.3 & 0.0748 & 0.0952 & 0.0884 \\
0.40 & 8.0 & 0.0498 & 0.0629 & 0.0585 \\
0.50 & 6.5 & 0.0401 & 0.0503 & 0.0469 \\
0.60 & 5.0 & 0.0313 & 0.0390 & 0.0364 \\
0.80 & 2.4 & 0.0152 & 0.0188 & 0.0176 \\
& & & & \\
\hline
\end{tabular}

Table 5b. Refractive index reliability

One location of referral piece measured four times. Four locations of suspect piece measured four times.

$$
\sigma_{D}=6.61 \times 10^{-5}
$$

\begin{tabular}{lllll}
\hline$\alpha$ & $C_{x 10^{5}}$ & \multicolumn{1}{c}{$\beta_{1}$} & $\beta_{2}$ & $\beta$ \\
\hline & & & & \\
0.001 & 21.8 & 0.125 & 0.165 & 0.152 \\
0.004 & 19.0 & 0.112 & 0.145 & 0.134 \\
0.008 & 17.5 & 0.104 & 0.134 & 0.124 \\
0.010 & 17.0 & 0.101 & 0.131 & 0.121 \\
0.040 & 15.4 & 0.0924 & 0.118 & 0.109 \\
0.050 & 13.6 & 0.0824 & 0.105 & 0.0975 \\
0.060 & 13.0 & 0.0788 & 0.100 & 0.0929 \\
0.080 & 12.4 & 0.0757 & 0.0963 & 0.0894 \\
0.10 & 11.6 & 0.0708 & 0.0898 & 0.0835 \\
0.20 & 10.9 & 0.0666 & 0.0847 & 0.0787 \\
0.40 & 8.5 & 0.0523 & 0.0662 & 0.0616 \\
0.50 & 5.6 & 0.0346 & 0.0435 & 0.0405 \\
0.60 & 4.5 & 0.0279 & 0.0349 & 0.0326 \\
0.80 & 3.5 & 0.0216 & 0.0271 & 0.0253 \\
& 1.7 & 0.0105 & 0.0132 & 0.0123 \\
\hline
\end{tabular}


Table 5c. Refractive index reliability

Four locations of referral piece measured four times. Four locations of suspect piece measured four times.

$$
\sigma_{D}=4.18 \times 10^{-5}
$$

\begin{tabular}{ccccc}
\hline$\alpha$ & $C \times 10^{5}$ & $\beta_{1}$ & $\beta_{2}$ & $\beta$ \\
\hline 0.001 & 13.8 & 0.0834 & 0.106 & 0.0985 \\
0.004 & 12.0 & 0.0734 & 0.0934 & 0.0867 \\
0.008 & 11.1 & 0.0680 & 0.0861 & 0.0801 \\
0.010 & 10.8 & 0.0661 & 0.0836 & 0.0778 \\
0.020 & 9.7 & 0.0599 & 0.0758 & 0.0705 \\
0.040 & 8.6 & 0.0531 & 0.0670 & 0.0624 \\
0.050 & 8.2 & 0.0507 & 0.0640 & 0.0596 \\
0.060 & 7.9 & 0.0487 & 0.0614 & 0.0572 \\
0.080 & 7.4 & 0.0454 & 0.0570 & 0.0531 \\
0.10 & 6.9 & 0.0427 & 0.0536 & 0.0500 \\
0.20 & 5.4 & 0.0334 & 0.0419 & 0.0391 \\
0.40 & 3.5 & 0.0220 & 0.0275 & 0.0257 \\
0.50 & 2.8 & 0.0176 & 0.0221 & 0.0206 \\
0.60 & 2.2 & 0.0137 & 0.0172 & 0.0160 \\
0.80 & 1.1 & 0.0066 & 0.0083 & 0.0077 \\
\hline
\end{tabular}

Table 5d. Refractive index reliability

Four locations of referral piece measured 10 times. Eight locations of suspect piece measured 10 times.

$$
\sigma_{D}=3.51 \times 10^{-5}
$$

\begin{tabular}{crccc}
\hline$\alpha$ & $C \times 10^{5}$ & $\beta_{1}$ & $\beta_{2}$ & $\beta$ \\
\hline 0.001 & 11.5 & 0.0707 & 0.0896 & 0.0833 \\
0.004 & 10.1 & 0.0622 & 0.0786 & 0.0731 \\
0.008 & 9.3 & 0.0574 & 0.0725 & 0.0675 \\
0.010 & 9.0 & 0.0558 & 0.0704 & 0.0655 \\
0.020 & 8.2 & 0.0506 & 0.0637 & 0.0593 \\
0.040 & 7.2 & 0.0448 & 0.0563 & 0.0525 \\
0.050 & 6.9 & 0.0428 & 0.0538 & 0.0501 \\
0.060 & 6.6 & 0.0411 & 0.0516 & 0.0481 \\
0.080 & 6.1 & 0.0383 & 0.0480 & 0.0448 \\
0.10 & 5.8 & 0.0359 & 0.0451 & 0.0420 \\
0.20 & 4.5 & 0.0281 & 0.0352 & 0.0328 \\
0.40 & 3.0 & 0.0185 & 0.0231 & 0.0216 \\
0.50 & 2.4 & 0.0148 & 0.0185 & 0.0173 \\
0.60 & 1.8 & 0.0115 & 0.0144 & 0.0134 \\
0.80 & 0.9 & 0.00556 & 0.00696 & 0.0065 \\
& & & & \\
\hline
\end{tabular}


We next determine a criterion, $c$, which the difference $\left|\bar{x}_{1}-\bar{x}_{2}\right|$ must not exceed if the two pieces are to be declared matching. Assuming a Normally distributed population, we do this by finding the value for $z$ for which $1-\Phi(z)=\alpha / 2$. where, as before, $\phi(z)$ is the area under the Normal density curve from $-\infty$ to $z$. For example, if $a$ is taken to be $0.05, z=+1.96$. The criterion $C$ is then equal to $z^{\circ} \sigma^{\circ}$

$\sigma_{\mathrm{D}}$ can be reduced by making more measurements at more locations on both the referral and suspect fragments. However, as can be seen from table 6 , there is a limit to this reduction.

Table 6. Dependence of $\sigma_{D}$ on the number of measurements

$$
\sigma_{i}=5.6 \times 10^{-5} \quad \sigma_{m}=3.8 \times 10^{-5}
$$

RI measurements taken to fifth decimal place

\begin{tabular}{lllll}
\hline$m_{r}$ & $m_{s}$ & $n_{r}$ & $n_{s}$ & $\sigma_{D} \times 10^{5}$ \\
\hline 1 & 1 & 1 & 1 & 9.57 \\
1 & 4 & 4 & 4 & 6.61 \\
4 & 4 & 4 & 4 & 4.18 \\
4 & 8 & 5 & 5 & 3.58 \\
4 & 8 & 10 & 10 & 3.51 \\
\hline
\end{tabular}

There will be a false match if a match is declared between the referral fragment and a fragment from any other lens. For simplicity, consider first only the late Corning subpopulation. Its mean RI is 1.47476. There will be more lenses with RI's close to that value, say within $\pm 1 \times 10^{-5}$, than will be that close to any other value. Hence $B$ will be a maximum if the referral fragment RI should measure 1.47476 .

To calculate $B$ exactly, an integration must be made over the distribution of late Corning lenses, but approximations correct to two decimal places can be computed by calculating the probability that a randomly selected lens from the late Corning population will have a true mean RI within C of the true mean RI of the referral fragment. For a fragment with mean RI equal to the population mean, this probability is the two-sided value $\Phi\left(C / \sigma_{p}\right)-\Phi\left(-C / \sigma_{p}\right)=$ $2 \Phi\left(C / \sigma_{p}\right)-1=B^{*}$ say. Since the average height of a Normal density function is $y \sqrt{2}$ times the maximum height (at the mean), we multiply $B^{*}$ by $1 / \sqrt{2}$ to allow for RI's different from the mean. 
Account is taken of the fact that there are three subpopulations in the same way as in section 6.2.1.1. If the referral fragment happens to be from a late Corning lens, only one-third of all the lenses on the road will have a chance of false acceptance so that $\beta_{1}=B_{1} * /(3 \sqrt{2})$. Or if the referral fragment happens to be from an early Corning or GE lens, only two-thirds of all the lenses on the road will have a chance of false acceptance so that $B_{2}=2 \beta_{2} * /$ $(3 \sqrt{2})$. The first situation will occur about one-third of the time, the second about two-thirds of the time. Then, for the entire population, the average is :

$$
B=\frac{1}{3} B_{1} * /(3 \sqrt{2})+\frac{2}{3} \sqrt{2} B_{2} * / 3
$$

Tables $5 \mathrm{a}$ through $5 \mathrm{~d}$ show $\alpha$ and $\beta$ values, together with corresponding values of $C$, for the four cases plotted in figure 7.5 Table 7 summarizes the steps used to calculate $\beta$ for a specified $\alpha$.

\subsection{Position Effect}

To check for the possibility that the process of molding the lens configuration might affect the RI variability from point to point within the lenses, RI's of corners of 17 rectangles from two different lenses were measured by one operator. The values were analyzed by angular position and by their radial distance from the lens center. No correlation was found for either set and it was concluded that the position of a specimen within the lens has no significant sffect on its RI value.

Table 7. Summary of steps to find $\beta$ for given $\alpha$

RI data measured to fifth decimal place. Refer to text for definitions of symbols.

1. Find $z$ such that $1-\Phi(z)=\alpha / 2$

2. $C=\mathrm{z} \sigma_{\mathrm{D}}$

3. $B_{1}^{*}=2 \Phi\left(C / \sigma_{1}\right)-1$

$$
B_{2}^{*}=2 \Phi\left(C / \sigma_{2}\right)-1
$$

4. $B_{1}=B_{1} * / 3 \sqrt{2}$

$$
B_{2}=2 B_{2} * / 3 \sqrt{2}
$$

5. $B=\frac{1}{3} B_{1}+\frac{2}{3} B_{2}$

${ }^{5}$ As in section 6.2 .1 , differences between $\mathrm{GE}$ and early Corning lenses allow a slight reduction in the $\beta$ values calculated here. Details are in appendix $B$. 


\subsection{Annealing}

Preliminary results of RI measurements on the 71 lenses showed a spread of about $20 \times 10^{-5}\left(\sigma_{L}=6.8 \times 10^{-5}\right)$ in $\mathrm{RI}$ values across any single lens. It was hoped that heating the specimens to about $500^{\circ} \mathrm{C}$ followed by slow cooling would reduce this spread, presumably by equalizing internal stresses. A group of pieces from 21 lenses selected to cover the range of spreads found earlier were subjected to such annealing. For some pieces there were changes in the fifth decimal place, but no statistically significant improvement was found. The presence of striations with RI differing from the rest of the piece may account for these results.

Pieces from 11 lenses in this group were annealed again at a higher temperature for a longer time. The RI values were markedly reduced, but with increase of spread. Examination with an electron microscope indicated there had been a separation into silica-rich and boron-rich phases. In view of the unpredictability of annealing effects, the treatment is not recommended for characterization studies of headlamp glass.

\subsection{Dispersion}

Because light of different colors (wavelengths) travels at different velocities in a transparent medium, the refractive index $n$ will be found to have lower values for the longer wavelengths in the red region of the spectrum than for the shorter wavelengths in the blue. The effect is called. dispersion. It is known that various types of glass differ significantly in this regard, and measurements made with red, yellow, and blue light will serve to distinguish headlamp glass from window glass, bottle glass, or optical glass.

Dispersion measurements made at NBS were based on illumination sources preferred for their spectral purity: cadmium red $C^{\prime}(0.6438 \mu \mathrm{m})$, sodium yellow doublet $D(0.5893 \mu \mathrm{m})$, and cadmium blue $\mathrm{F}^{\prime}(0.4800 \mu \mathrm{m})$. Dispersion is often expressed in terms of differences in refractive index values measured at several wavelengths. In this study, these RI differences did not vary appreciably from headlight to headlight. More specifically, at least 18 measurements were made of both $n_{D}$ and $n_{C}{ }^{\prime}$ for each of 12 different lenses. The average range of measurements within a lens for $C^{\prime}$ was $20 \times 10^{-5}$, and for $D, 17 \times 10^{-5}$; the range over all 12 lenses was $468 \times 10^{-5}$ and $464 \times 10^{-5}$ respectively, allowing some discrimination between lenses. On the other hand, the average range within a lens of the difference $n_{C}{ }^{-} n_{D}$ was $10 \times 10^{-5}$; the range over all lenses was only $22 \times 10^{-5}$. Thus the difference $n_{C}-n_{D}$ varies within a lens by an amount that is almost half its total population variation. Therefore, dispersion is not a sensitive parameter for either classifying or individualizing auto headlight glasses. That is, dispersion cannot be used effectively to distinguish one auto headlight from another. The measured RI differences were typically $182 \times 10^{-5}$ for $n\left(D-C^{\prime}\right), 734 \times 10^{-5}$ for $n\left(F^{\prime}-C^{\prime}\right)$, and $553 \times 1 n^{-5}$ for $n\left(F^{\prime}-D\right)$. The Abbe number, defined as

$$
v=\frac{n_{D}-1}{n_{F^{\prime}}-n_{C}{ }^{\prime}}
$$

is about 65 .

\subsection{Temperature Coefficient of Refractive Index and Thermal coefficient of Expansion}

The temperature coefficient of refractive index and the thermal coefficient of expansion must be known when using a "hot stage" method of measuring refractive index and density. It is known that the RI of borosilicate glass changes with temperature, partly because of the change in density, and partly because of a shift in the ultraviolet absorption band which is characteristic of the chemical composition. 
The NBS automatic fringe-recording interferograph developed by Saunders [11] can measure simultaneously both $\mathrm{dn} / \mathrm{d} T$ and the thermal coefficient of expansion. For one piece of the headlamp samples, the latter was found to be $3.88 \times 10^{-6} /{ }^{\circ} \mathrm{C}$ over a broad range of temperature, and $\mathrm{dn} / \mathrm{dT}$ was found to be $5.3 \times 10^{-6} /{ }^{\circ} \mathrm{C}$ at $0.5893 \mu \mathrm{m}$ between $20^{\circ}$ and $80^{\circ} \mathrm{C}$. This positive coefficient disagrees with the estimated $-6.5 \times 10^{-6} /{ }^{\circ} \mathrm{C}$ reportad for $0.589 \mu \mathrm{m}$ between 20 and $40^{\circ} \mathrm{C}$ by Ojena and DeForest [8].

\section{DENSITY MEASUREMENTS}

In addition to RI, another physical property widely used to characterize glass is its density. The NBS refractive index standard reference glass No. 1820 has a density of $2.292+0.001 \mathrm{~g} / \mathrm{cm}^{3}$ at $24^{\circ} \mathrm{C}, 50$ percent relative humidity, and a pressure of $99,442 \mathrm{~Pa}(746 \mathrm{~mm} \mathrm{Hg})$.

That there is strong correlation between density and RI, both at room temperature and at annealing temperatures, was indicated for optical glass by Tool, Tilton and Saunders [12]. Density was one of the properties measured by Nelson [13] in an individualization study of 50 Lucas 700 headlamp fragments. He obtained a standard deviation of $0.001 \mathrm{~g} / \mathrm{cm}^{3}$ for six repeated. determinations, estimating an accuracy of $+0.002 \mathrm{~g} / \mathrm{cm}^{3}$. However, when two pieces had nearly the same density he made comparative measurements (with a sensitivity of $0.0005 \mathrm{~g} / \mathrm{cm}^{3}$ ), which succeeded in distinguishing all but two pairs out of the 50 .

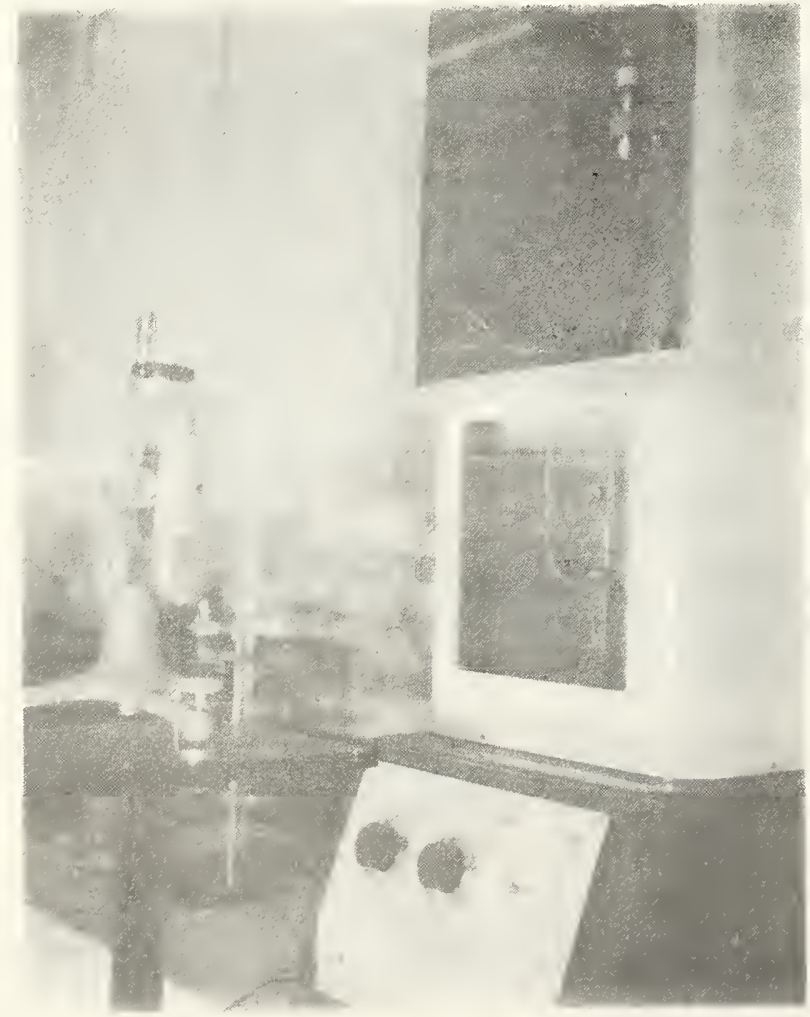

Figure 8. Sink-float density apparatus. 
The density measurements for the NBS study were obtained by the sink/float method. The density liquid was made by combining STetrabromethane and Isopropyl salicylate acid, in proportions designed to match the density of the sample at about $20^{\circ} \mathrm{C}$. A mixture of $64 \mathrm{~mL}$ of STetrabromethane and $3.86 \mathrm{~mL}$ of Isopropyl Salicylate acid was found suitable. The density liquid was calibrated at higher temperatures with a series of density standards, before and during the actual test runs.

The density liquid was held in a U-tube as shown in figure 8; the U-tube, in turn, was mounted in a temperature-controlled water bath. The temperature of the liquid was monitored by a resistance thermometer which was held in one arm of the U-tube. The sample was held in a wire cage in the other arm of the U-tube and observed for change in position via a traveling cathetometer. The test procedure was to raise the temperature of the bath at a rate of approximately $0.0035^{\circ} \mathrm{C} / \mathrm{min}$ until the sample changed from a floating to a sinking condition.

Two pieces of glass from each of 12 headlamp lenses were measured, covering all three subpopulations (late Corning, early Corning, and GE). Lenses were selected having a range of standard deviations for RI; these had been subjected to various amounts of annealing, and covered the range of RI values found. These were arranged in an appropriate order such that any effects due to time (e.g., instrument drift) would not be mixed with effects due to manufacturer, annealing, etc. Values of density and RI are shown in table 8 .

Table 8. Data on first 24 density measurements and four repeats.

\begin{tabular}{|c|c|c|c|c|c|c|}
\hline $\begin{array}{l}\text { Order of } \\
\text { measurement }\end{array}$ & Lens & Piece & $\operatorname{Mfr} .^{a}$ & $\begin{array}{l}\text { Refractive } \\
\text { index }\end{array}$ & \multicolumn{2}{|c|}{$\begin{array}{c}\text { Density/repeat } \\
\mathrm{g} / \mathrm{cm}^{3}\end{array}$} \\
\hline 1 & 11 & $\alpha$ & 1 & 1.47498 & $2.25226 / 2$ & 25448 \\
\hline 2 & 151 & $E$ & 2 & 545 & 5264 & \\
\hline 3 & 12 & D & 3 & 147 & $2952 /$ & 2918 \\
\hline 4 & 129 & $\alpha$ & 2 & 664 & 6358 & \\
\hline 5 & 27 & $\mathrm{~J}$ & 3 & 264 & 3689 & \\
\hline 6 & 149 & $\varepsilon$ & 1 & 665 & 6606 & \\
\hline 7 & 5 & $\varepsilon$ & 1 & 733 & 6844 & \\
\hline 8 & 3 & D & 3 & 354 & 3884 & \\
\hline 9 & 104 & $\mu$ & 2 & 604 & 5788 & \\
\hline 10 & 8 & $\alpha$ & 3 & 249 & 3438 & \\
\hline 11 & 39 & $\mathrm{~J}$ & 1 & 630 & 6189 & \\
\hline 12 & 145 & $\mathrm{E}$ & 2 & 463 & 5233 & \\
\hline 13 & 145 & $\mathrm{R}$ & 2 & 469 & 5245 & \\
\hline 14 & 39 & L & 1 & 613 & 6073 & \\
\hline 15 & 8 & $\lambda$ & 3 & 240 & 3381 & \\
\hline 16 & 104 & $\varepsilon$ & 2 & 610 & 5761 & \\
\hline 17 & 3 & L & 3 & 355 & 3884 & \\
\hline 18 & 5 & $\mu$ & 1 & 724 & 6841 & \\
\hline 19 & 149 & $\lambda$ & 1 & 658 & 6584 & \\
\hline 20 & 27 & $\mathrm{P}$ & 3 & 260 & 3720 & \\
\hline 21 & 129 & $\mu$ & 2 & 673 & 6384 & \\
\hline 22 & 12 & J & 3 & 155 & $2746 /$ & 2705 \\
\hline 23 & 151 & L & 2 & 557 & $5378^{\circ}$ & \\
\hline 24 & 11 & $\delta$ & 1 & 517 & $5507 /$ & 5456 \\
\hline
\end{tabular}

ate: Mfr. $1=$ General Electric

Mfr. 2 = Early Corning

Mfr. 3 = Late Corning 


\section{ANALYSIS OF DENSITY DATA}

Various plots and analyses of the data of table 8 were performed, revealing no discernible instrument drift, but casting suspicion on a few of the values. Accordingly, four measurements were repeated. Based upon the estimated measurement-error s.d. of $15 \times 10^{-5} \mathrm{~g} / \mathrm{cm}^{3}$ for a single measurement, three of these repeat measurements agreed (at the $5 \%$ significance level) with the initial readings. The repeat value of the measurement labeled \#1 was significantly different (at the $0.02 \%$ significance level) from the initial value; the remeasured value (2.25448) was used in place of the original value $(2.25226)$.

The correlation between RI and density was found to be 0.99. This high correlation obviated the necessity for an independent population study of density, since density values for the purpose of determining population parameters can be predicted quite adequately from RI values.

Because of this high correlation, forensic scientists should not consider refractive index and density measurements as independent types of physical evidence when characterizing auto headlight glass. That is, assuming for the moment that RI and density measurements have comparable inherent reliabilities, $m$ RI measurements and $n$ density measurements on a single lens are equivalent to $(m+n)$ of either refractive index or density measurements.

The regression equation is

Density Value $=-8.09+7.01 x($ RI Value $)$

For classification of headlamp glasses, density and refractive index are equivalent.

For individualization, however, density could be a more useful property than RI if the inhomogeneity of the lens; as represented by $\sigma_{i}$, was less for density; if the standard deviation of the measurement error $\sigma_{\mathrm{m}}$ was smaller; or if readings could be taken easily to more decimal places. To estimate the standard deviation for density measurements across a lens, seven pieces of glass from each of the four lenses were measured to the nearest $0.3 \times 10^{-5}$. The resulting estimate of $\sigma_{L}$ was $26.7 \times 10^{-5}$, with 90 percent confidence limits at $33.4 \times 10^{-5}$ and $20.0 \times 10^{-5}$. Also, there were five repeat measurements made at different times, from which the measurement error component $\sigma_{\mathrm{m}}$ was estimated to be $15 \times 10^{-5}$. Since $(26.7)^{2}-(15)^{2} \simeq(22)^{2}$, an estimate of the standard deviation $\left(\sigma_{i}\right)$ due to inhomogeneity of a lens is $22 \times 10^{-5}$. (This discussion parallels the discussion for RI in section 6.2. )

To compare fairly the relative sizes of the lens standard deviations corresponding to refractive index and density, the RI standard deviation should be multiplied by 7.01 (because it is the ratio $\sigma_{\mathrm{L}} / \sigma_{\mathrm{P}}$ that counts, and the population standard deviation is 7.01 times larger for density than for RI; see the regression equation above). This multiplication and comparison is shown in table 9. It will be seen that the standard deviation due to inhomogeneity of density is about 55 percent of the product $7.01 \times$ the standard deviation for RI; the same ratio holds for the measurement error standard deviation. Thus, it appears worthwhile to apply the reliability analysis of section 6.2 to these data for density, coupled with population estimates of $\sigma_{1}=7.01 \times 30 \times 10^{-5}$ for late Corning glass, and $\sigma_{2}=7.01 \times 48 \times 10^{-5}$ for the other subpopulation. 
Table 9. Comparisons of refractive index and density standard deviations

Refractive
index at
$0.58926 \mu \mathrm{m}$$$
\text { RI value }
$$$$
\times 7.01
$$

Density

measurement $\mathrm{g} / \mathrm{cm}^{3}$
Est. std. dev. of measurements at random points across a lens, $\sigma_{\mathrm{L}}$

Est. sta. dev. of measurement error, $\sigma_{\mathrm{m}}$

Est. std. dev. due to inhomogeneity in a lens, $\sigma_{i}$

$$
6.8 \times 10^{-5}
$$$$
3.8 \times 10^{-5}
$$

$\begin{array}{lll}6.8 \times 10^{-5} & 48 \times 10^{-5} & 26.7 \times 10^{-5} \\ 3.8 \times 10^{-5} & 27 \times 10^{-5} & 15 \times 10^{-5} \\ 5.6 \times 10^{-5} & 39 \times 10^{-5} & 22 \times 10^{-5}\end{array}$

For one density measurement of both the hypothetical referral fragment and its suspected source, we may write as before:

$$
\begin{aligned}
\sigma_{D}^{2} & =2\left(22 \times 10^{-5}\right)^{2}+2\left(15 \times 10^{-5}\right)^{2} \\
& =\left(37.66 \times 10^{-5}\right)^{2}
\end{aligned}
$$

Computed $\alpha$ and $B$ values--comparable with those in table $5 a--a r e$ tabulated in table 10 and plotted in figure 7. There appears to be significant improvement in the reliability of density measurements compared to the reliability of corresponding refractive index measurements.

\section{CONCLUSIONS AND UPDATE}

This section presents conclusions in terms of the defined average error probabilities $\alpha$ (the chance that the lens which does in fact match the referral piece will falsely be declared nonmatching) and $B$ (the chance that a randomly-selected, nonmatching lens will falsely be declared matching). Either of these two error probabilities can be decreased, at the expense of increasing the other, by changing the criterion for a match. Furthermore, both can be decreased (up to a point) by taking more measurements on more pieces of glass; however, since the referral piece is often small, we have not considered multiple referral pieces.

The top curve in figure 7 represents the available $(\alpha, \beta)$-pairs using RI, with one piece from the suspect lens and one measurement on it (and one measurement on the referral piece), as of the time the analyses were originally done. Representative $(\alpha, \beta)$ values from this curve are $(.001, .21)$; $(.025, .15) ;(0.5 ; .13) ;(.11, .11)$; and $(.48, .05)$. It is seen that decreasing $B$ costs dearly in terms of $\alpha$. Changes due to more samples and/or measurements, to using density instead of RI, and to changes in the basic population of lenses on the road, are most conveniently expressed in terms of factors which modify $\beta$ for any given $\alpha$ (i.e., which raise or lower the top curve in figure 7. since the scales are logarithmic). Such a representation is close to exact, as long as both errors are below (say) 50 percent. 
Table 10. Density reliability.

One location of referral piece measured one time.

One location of suspect piece measured one time.

$$
\sigma_{D}=37.66 \times 10^{-5} \mathrm{~g} / \mathrm{cm}^{3}
$$

\begin{tabular}{lrccc}
\hline$\alpha$ & $\begin{array}{c}\mathrm{C} \times 10^{5} \\
\left(\mathrm{~g} / \mathrm{cm}^{3}\right)\end{array}$ & $B_{1}$ & $B_{2}$ & $B$ \\
\hline 0.001 & 123.9 & 0.105 & 0.135 & 0.125 \\
0.004 & 108.4 & 0.0928 & 0.119 & 0.110 \\
0.008 & 99.9 & 0.0861 & 0.110 & 0.102 \\
0.010 & 97.0 & 0.0838 & 0.107 & 0.0991 \\
0.020 & 87.6 & 0.0762 & 0.0969 & 0.0900 \\
0.040 & 77.4 & 0.0677 & 0.0857 & 0.0797 \\
0.050 & 73.8 & 0.0647 & 0.0819 & 0.0762 \\
0.060 & 70.8 & 0.0622 & 0.0786 & 0.0731 \\
0.080 & 65.9 & 0.0580 & 0.0732 & 0.0681 \\
0.10 & 62.0 & 0.0546 & 0.0689 & 0.0641 \\
0.20 & 48.3 & 0.0428 & 0.0538 & 0.0501 \\
0.40 & 31.7 & 0.0282 & 0.0354 & 0.0354 \\
0.50 & 25.4 & 0.0226 & 0.0284 & 0.0265 \\
0.60 & 19.7 & 0.0176 & 0.0220 & 0.0205 \\
0.80 & 9.5 & 0.00851 & 0.0106 & 0.00990 \\
\hline
\end{tabular}

Taking four measurements on each of four pieces from the suspect lens and on the referral piece results in decreasing $B$ by a factor 0.71 . Using density instead of RI decreases $B$ by a factor of 0.55 . Finally, if the variation within a lens and the variation across a subpopulation both remain at the values observed in this study, but the subpopulations are shifted till they coincide (a conservative assumption), then $\beta$-values are increased by at most a factor of 1.8. These factors can be applied sequentially. Thus, since it happens that $0.55 \times 1.8=1.0$, the top two curves in figure 7 represent not only the $(\alpha, \beta)$ pairs available in 1975, using RI, but also (upper bounds on) the values available today using density.

Firally, it should be noted that conclusions regarding the reliability of refractive index and density measurements to characterize auto headlight glass should not be made on the basis of measurements of om at NBS. $\sigma_{m}$ may be quite different for measurements made in forensic laboratories under the pressures of producing evidence for actual criminal investigations. Meaningful values of $\sigma_{m}$ for this purpose, for both refractive index and density, can best be measured in forensic laboratory proficiency tests. The ${ }^{\circ} \mathrm{m}$ values computed in this study, again for both refractive index and density, are of interest as "best case" values. Larger values of om, which are probably encountered in real criminal investigations, will degrade the reliability that can be expected. 


\section{APPENDIX A- "TRIAL BY MATHEMATICS"}

This appendix quotes from a paper by Laurence H. Tribe, "Trial by Mathematics: Precision and Retrial in the Legal Process" [14] concerning the wisdom of the use of statistical methods in the trial process. The first two quotations are representative of the concerns expressed: "...the very system that surrounds mathematical arguments--the relative obscurity that makes them at once impenetrable by the layman and impressive to him--creates a continuing risk that he will give such arguments a credence they may not deserve and a weight they cannot logically claim" [15]. "...in at least some contexts, permitting any use of certain mathematical methods entails a sufficiently high risk of misuse sufficiently costly to avoid, that it would be irrational not to take such misuse into account when deciding whether to permit the methods to be employed at all." [16]. Continuing to quote Tribe, "With the possible exception...of using evidence as to frequencies in order to negate a misleading impression of unequalness that expert opinion might otherwise convey, I think it fair to say that the costs of attempting to integrate mathematics into the factfinding process of a legal trial outweigh the benefits" [17]. The exception mentioned here is the use to which the statistics used in this report are applied. In a footnote, Tribe writes, "...the most common defensive use (of mathematical methods) would probably be the translation into quantitative form of an expert's damaging opinion that a certain physical trace or combination of traces must 'almost certainly' have been left by the accused. ...Courts otherwise hostile to probabilistic proof have at times allowed such quantification of expert opinion about trace evidence even at the prosecutor's initiation. ...And, once such quantification has been initiated by the defense, the case for allowing the prosecution to rebut in mathematical terms becomes quite persuasive." [18]. 


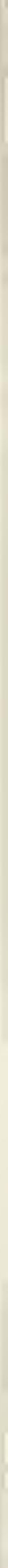


The derivations in the body of this report were performed using a model which said that the distributions for $\mathrm{GE}$ lenses and for early Corning lenses were identical. Actually, although there is a good deal of overlap, the two means are significantly different. (The standard deviations are not significantly different.) Thus the number of lenses that are candidates for false match is smaller than assumed. To account for this fact, we need to take a more complicated approach than that used before.

Let $x$ be the RI of the referral piece. $x$ is a random variable with a Normal distribution $F_{1}$, with given mean $\mu_{1}$ and variance $\sigma^{2}$. Let $\mu_{2}$ represent the mean of another (overlapping) distribution $F_{2}$ with the same variance. For a given value of $x$, the probability of drawing a matching piece from $F_{1}$ is $F_{1}(x+c)-F_{1}(x-c)$, where $c$ is the criterion for a match. We can replace this expression by $2 \mathrm{cf}_{1}(x)$, where $f_{l}(x)$ is the probability density function, since $c$ is small with respect to $\sigma$. Similarly, $2 \mathrm{cf}_{2}(\mathrm{x})$ is the probability that a random piece from $F_{2}$ will match. Since the two subpopulations are each assumed to contain one-third of the existing lenses, the total probability of drawing a (false) match is $1 / 3\left(2 \operatorname{cf}_{1}(x)\right)+1 / 3\left(2 \mathrm{cf}_{2}(x)\right)$; we must average this expression over the possible values of $x$. Thus we have

$$
\begin{aligned}
B_{2}= & \int_{-\infty}^{\infty} \frac{1}{\sqrt{2 \pi \sigma}} e^{-(1 / 2)\left(\frac{x-\mu_{1}}{\sigma}\right)^{2}} \times \\
& {\left[\frac{2 c}{3 \sqrt{2 \pi} \sigma} e^{-(1 / 2)\left(\frac{x-\mu_{1}}{\sigma}\right)^{2}}+\frac{2 c}{3 \sqrt{2 \pi} \sigma} e^{\left.-(1 / 2)\left(\frac{x-\mu_{2}}{\sigma}\right)^{2}\right]} d x .\right.}
\end{aligned}
$$

Substituting $t=\frac{x-\mu_{1}}{\sigma}$, we obtain

$$
\begin{aligned}
B_{2} & =\frac{2 c}{3} \int_{-\infty}^{\infty} \phi(t)\left[\phi(t)+\phi\left(t-\left(\frac{\mu_{2}-\mu_{1}}{\sigma}\right)\right)\right] d t \\
& =\frac{2 c}{3}\left(\frac{1}{2 \sqrt{\pi}}\right)\left(1+e\left(\frac{\mu_{2}-\mu_{1}}{2 \sigma}\right)^{2}\right)
\end{aligned}
$$


where $\phi(t)=(2 \pi)^{-1 / 2} \exp \left(-t^{2} / 2\right)$ is the standardized Normal density function. With $\mu_{1}=\mu_{2}$, we get $B_{2}=\frac{2 c}{3 \sqrt{\pi}}$.

Thus the $B_{2}$ values we had should be multiplied by a factor

$$
\frac{1+\exp -.79}{2}=0.727
$$

Now $B_{1}$ does not change, so the change in $B_{2}$ affects $B$ as follows:

$$
B=\frac{1}{3} B_{1}+\frac{2}{3} B_{2}
$$

which becomes

$$
B=\frac{1}{3} B_{1}+\frac{2}{3}\left(.727 B_{2}\right)
$$

Since $B_{2}=\frac{4}{3} B_{1}$ (approximately), $B$ is changed from

$$
\frac{1}{3} B_{1}+\frac{2}{3}\left(\frac{4}{3} B_{1}\right)
$$

to

$$
\frac{1}{3} B_{1}+\frac{2}{3}(.727) \frac{4}{3} B_{1}
$$

Thus the correction factor to be applied to the $B$ values already calculated is

$$
\left[\frac{1}{3}+\frac{2}{3}(.727) \frac{4}{3}\right] \div\left[\frac{1}{3}+\frac{2}{3}\left(\frac{4}{3}\right)\right]=0.80
$$


[1] Greene, R. S.; Burd, D. Q. Headlight glass as evidence. J. Crím. Law, Criminol. Police Sci. 40: 85; 1949.

[2] Allen, R. M. Practical refractometry by means of the microscope. 1962. Available from Cargille Laboratories, Minneapolis, MN 55440.

[3] Saylor, C. P. Accuracy of microscopical methods for determining refractive index by immersion. J. Res. Nat. Bur. Stand. (U.S.). 15: $277 ; 1935$.

[4] Faick, C. A.; Foronoff, B. A precision apparatus for the rapid determination of indices of refraction and dispersion by immersion. J. Res. Nat. Bur. Stand. (U.S.) . 32: 67; 1944 .

[5] Dabbs, M. D. G.; Pearson, E. F. The hot stage microscope. Central Research Establishment Report No. 26; 1969. Available from the Home office, Central Research Establishment, Reading, Berkshire, England, R974PN.

[6] Dixon, B. M. Use of the Mettler FP-2 for RI determinations. J. Can. Soc. Forensic Sci. 9: 115; 1970.

[7] Ojena, S. M.; DeForest, P. R. Precise refractive index determinations by the immersion method using phase contrast microscopy and the Mettler hot stage. J. Forensic Sci. 17: 315; 1972.

[8] Ojena, S. M.; Deforest, P. R. A study of the refractive index variations within and between sealed beam headlights using a precise method. J. Forensic Sci. 17: 409; 1972 .

[9] McCrone, W. C. Microscopical characterization of glass fragments. J. Assoc. Off. Anal. Chem. 55: 834; 1972 .

[10] McCrone, W. C. Collaborative study of the microscopical characterization of glass fragments. J.Assoc. Off. Anal. Chem. 56: $1223 ; 1973$.

[11] Saunders, J. B. An apparatus for photographing interference phenomena. J. Res. Nat. Bur. Stand. (U.S.). 35: 157; 1945.

[12] Tool, A. Q.; Tilton, H. W.; Saunders, J. B. Changes caused in the refractivity and density of glass by annealing. J. Res. Nat. Bur. Stand. (U.S.). 38: 519; 1947 .

[13] Nelson, D. F. The identification of Lucas 700 headlamp glass fragments by their physical properties. Analyst. 84(999): 388-392; 1959.

[14] Tribe, L. H. Trial by mathematics: precision and ritual in the legal process. Harvard Law Rev. 84(6): 1329-1393; 1971.

[15] Ibid, p. 1334 .

[16] Ibid, p. 1331.

[17] Ibid, p. 1377 .

[18] Ibid, p. 1377. 
SHEET (See instructions)

1. PUBLICATION OR REPORT NO.

NBSIR 81-2286
2. Performing Organ, Report Nof 3. Publication Date

October 1981

4. TITLE AND SUBTITLE

The Characterization of Auto Headight Glass by

Refractive Index and Density

5. AUTHOR(S)

Law Enforcement Standards Laboratory

6. PERFORMING ORGANIZATION (If joint or other than NBS, see instructions)

NATIONAL BUREAU OF STANDARDS

DEPARTAENT OF COMMERCE

WASHINGTON, D.C. 20234

7. Contract/Grant No.

8. Type of Report \& Period Covered

Final

9. SPONSORING ORGANIZATIOW WANE ANO COMPLETE ADDRESS (Street, CHY, StUte, ZIP)

National Institute of Justice

U.S. Department of Justice

Washington, DC 20531

10. SUPPLEMENTARY NOTES

Document describes a computer program; SF-185, FIPS Software Summary, is attached.

11. ABSTRACT (A 200-word or less factual summary of most significant information. If document includes a significant bibliography or literature survey, mention it here)

By measurement of some physical property of headlight glass fragments found at the scene of an auto accident, forensic scientists have sometimes found it possible to infer that the glass was molded by a specific manufacturer, or even that it came from a broken headlamp on a specific car. The refractive index (RI) and density of the representative specimens are the most common parameters of interest to forensic scientists. In this study, performed in 1975, automotive headlights were obtained from several sources. From RI and density measurements, it is concluded that partial classification (by manufacturer and/or age) could be reliably achieved. There is less likelihood that an unknown fragment can be reliably individualized to a specific headlamp lens because of the inhomogeneity within each lens. The probability is not increased appreciably by taking repeated measurements, by annealing the specimens, by measuring RI at several wavelengths, or by measuring both RI and density.

12. KEY WOROS (Six to twelve entries; alphabetical order; capitalize only proper names; and separate key words by semicolons) auto headlight glass; classification; density; forensic science; individualization; population statistics; refractive index

13. AVAILABILITY

8 Unlimited

For Official Distribution. Do Not Release to NTIS

Order From Superintendent of Documents, U.S. Government Printing Office, Washington, D.C. 20402.

X. Order From National Technical Information Service (NTIS), Springfield, VA. 2216I
14. NO. OF PRINTED PAGES 37

15. Price 

